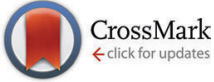

Cite this: Phys. Chem. Chem. Phys., 2016, 18, 28648

Received 2nd July 2016 Accepted 26th September 2016

DOI: $10.1039 / \mathrm{c} 6 \mathrm{cp} 04622 \mathrm{c}$

www.rsc.org/pccp

\section{Modelling the chemistry of $\mathrm{Mn}$-doped $\mathrm{MgO}$ for bulk and (100) surfaces $\dagger$}

\author{
Andrew J. Logsdail, ${ }^{* a b}$ Christopher A. Downing, ${ }^{\text {ac }}$ Thomas W. Keal, ${ }^{c}$ \\ Paul Sherwood, ${ }^{C}$ Alexey A. Sokol ${ }^{a}$ and C. Richard A. Catlow ${ }^{\text {abd }}$
}

\begin{abstract}
We have investigated the energetic properties of $\mathrm{Mn}$-doped $\mathrm{MgO}$ bulk and (100) surfaces using a QM/MM embedding computational method, calculating the formation energy for doped systems, as well as for surface defects, and the subsequent effect on chemical reactivity. Low-concentration $\mathrm{Mn}$ doping is endothermic for isovalent species in the bulk but exothermic for higher oxidation states under p-type conditions, and compensated by electrons going to the Fermi level rather than cation vacancies. The highest occupied dopant $\mathrm{Mn} 3 \mathrm{~d}$ states are positioned in the $\mathrm{MgO}$ band gap, about $4.2 \mathrm{eV}$ below the vacuum level. Surface $\mathrm{Mn}$-doping is more favourable than subsurface doping, and marginally exothermic on a (100) surface at high $\mathrm{O}_{2}$ pressures. For both types of isovalent $\mathrm{Mn}$-doped (100) surfaces, the formation energy for catalytically important oxygen defects is less than for pristine $\mathrm{MgO}$, with $\mathrm{F}^{\mathrm{O}}$ and $\mathrm{F}^{2+}$-centres favoured in $\mathrm{n}$ - and $\mathrm{p}$-type conditions, respectively. In addition, $\mathrm{F}^{+}$-centres are stabilised by favourable exchange coupling between the $\mathrm{Mn} 3 \mathrm{~d}$ states and the vacancy-localised electrons, as verified through calculation of the vertical ionisation potential. The adsorption of $\mathrm{CO}_{2}$ on to the pristine and defective (100) surface is used as a probe of chemical reactivity, with isovalent subsurface $\mathrm{Mn}$ dopants mildly affecting reactivity, whereas isovalent surface-positioned $\mathrm{Mn}$ strongly alters the chemical interactions between the substrate and adsorbate. The differing chemical reactivity, when compared to pristine $\mathrm{MgO}$, justifies further detailed investigations for more varied oxidation states and dopant species.
\end{abstract}

\section{Introduction}

Rocksalt alkali-earth oxides, such as $\mathrm{CaO}$ and $\mathrm{MgO}$, are amongst the materials currently under investigation for adsorbing and catalysing the transformation of $\mathrm{CO}_{2}{ }^{1,2}$ The bulk and surface structures of these oxides have been extensively studied,,$^{3-5}$ owing both to the simplicity of the rocksalt geometry and also the high degree of ionicity, which gives rise to a relatively simple electronic structure. ${ }^{6,7}$ Additionally, basic oxides such as MgO are popular as catalyst support materials but have displayed interesting reactivity when dopants or defects are included, ${ }^{8}$ which opens up the possibility for their use as catalysts in their own right. ${ }^{3,9-12}$

\footnotetext{
${ }^{a}$ Kathleen Lonsdale Materials Chemistry, Department of Chemistry, University College London, 20 Gordon Street, London, WC1H OAJ, UK. E-mail: a.logsdail@ucl.ac.uk; Tel: +44(0)20 76790312

${ }^{b}$ Cardiff Catalysis Institute, School of Chemistry, Cardiff University, Cardiff, CF10 3AT, UK

${ }^{c}$ Scientific Computing Department, STFC Daresbury Laboratory, Daresbury, Warrington, WA4 4AD, UK

${ }^{d}$ UK Catalysis Hub, Research Complex at Harwell, Science and Technology Facilities Council Rutherford Appleton Laboratory, Harwell Science and Innovation Campus, Oxon, OX11 OQX, UK $\dagger$ Electronic supplementary information (ESI) available: Additional data table with $\mathrm{CO}_{2}$ adsorption energies for pristine $\mathrm{Mn}-\mathrm{MgO}(100)$ surfaces. See DOI: 10.1039/ с6ср04622c
}

Whilst the surface chemistry and reactivity of $\mathrm{MgO}$ is well studied, only recently have investigations begun to show the potential of $\mathrm{MnO}$ in areas such as photocatalytic water splitting and $\mathrm{CO}_{2}$ reduction applications when alloyed with $\mathrm{ZnO},{ }^{13}$ and the (100) $\mathrm{MnO}$ surface has also been considered for $\mathrm{CO}_{2}$ adsorption as part of a systematic study of transition metal monoxides. ${ }^{14}$ The doping of rocksalt alkali-earth oxides with transition metals has proven to result in novel physical and catalytic properties ${ }^{15-17}$ and thus the catalytic reactivity of $\mathrm{MnO}$, coupled with the stability of the MgO surface, makes Mn-doped $\mathrm{MgO}$ an appealing material when designing novel catalytic systems. Furthermore, $\mathrm{Mn}^{2+}$ can directly replace $\mathrm{Mg}^{2+}$ without significant structural distortion as the ions are roughly equivalent in size; Mn-doped $\mathrm{MgO}$ is therefore structurally very similar to pristine $\mathrm{MgO}$ but can be differing in chemical reactivity, due to the range of stable oxidation states for the Mn-dopant. ${ }^{18-21}$

Previous studies on Mn-doped MgO, which we refer to henceforth as $\mathrm{Mn}-\mathrm{MgO}$, have focused on the enthalpies of mixing for $\mathrm{MgO}$ and $\mathrm{MnO},{ }^{22-24}$ which are generally positive (endothermic) and small $(<0.1 \mathrm{eV})$, as well as formation energies and defect properties for low concentration isovalent Mn-dopants with the aim of finding a dilute magnetic semiconductor (DMS) for use in spintronic applications. ${ }^{25-31}$ In particular, recent work has emphasised understanding the consequences of increasing 
Mn concentration and the coupling between extrinsic and intrinsic defects for both bulk and discrete systems. Experimental and modelling work by Azzaza et al. has shown that increasing the $\mathrm{Mn}$ content in $\mathrm{MgO}$ decreases the band gap and Curie temperature for dopant concentrations of 5 to $40 \%$, and magnetic interaction between isovalent $\mathrm{Mn}$ dopants and oxygen vacancies is postulated as influencing the stability. ${ }^{27}$ Panigrahi et al. showed via computation that isovalent Mn dopants are favourably positioned at (100) surfaces, rather than in the bulk, for an $\mathrm{MgO}$ slab model, and that short-range anti-parallel coupling between multiple Mn dopants is favoured in the absence of intrinsic defects; ${ }^{30}$ they then additionally highlighted that exchange coupling between isovalent Mn dopants and oxygen vacancies was also energetically favourable for bulk and surface models. ${ }^{30,31} \mathrm{MgO}$ surfaces are commonly host to significant concentrations of oxygen defects ${ }^{8,32}$ and, in the presence of the Mn 3d dopants, strong hybridisation between the Mn 3d and $\mathrm{O} 2 \mathrm{p}$ bands ${ }^{30}$ means that novel chemistry of the material could be driven by the interchange of electrons between the redox active manganese atom and oxygen vacancy, e.g.:

$$
\mathrm{Mn}^{+}+\mathrm{F}^{2+} \rightleftharpoons \mathrm{Mn}^{2+}+\mathrm{F}^{+} \rightleftharpoons \mathrm{Mn}^{3+}+\mathrm{F}^{0}
$$

The equilibrium in eqn (1) depends on both the ionisation potential and electron affinity for the F-centres and $\mathrm{Mn}^{+}, \mathrm{Mn}^{2+}$ and $\mathrm{Mn}^{3+}$ cations within the octahedrally coordinated lattice, with the lowest energy configuration taking precedence. For clarity, in Kröger-Vink notation, ${ }^{33}$ the $\mathrm{F}^{0}, \mathrm{~F}^{+}$and $\mathrm{F}^{2+}$-centres are denoted as $\mathrm{V}_{\mathrm{O}}^{\times}, \mathrm{V}_{\mathrm{O}}^{\bullet}$ and $\mathrm{V}_{\mathrm{O}}^{\bullet \bullet}$, respectively, and the equivalent equations are:

$$
\mathrm{Mn}_{\mathrm{Mg}}^{\prime}+\mathrm{V}_{\mathrm{O}}^{\bullet \bullet} \rightleftharpoons \mathrm{Mn}_{\mathrm{Mg}}^{\times}+\mathrm{V}_{\mathrm{O}}^{\bullet} \rightleftharpoons \mathrm{Mn}_{\mathrm{Mg}}^{\bullet}+\mathrm{V}_{\mathrm{O}}^{\times}
$$

In this work, we present high-level simulations of $\mathrm{Mn}-\mathrm{MgO}$, in order to elucidate the energetic and electronic properties of bulk- and surface-doped Mn-MgO. Firstly, formation energies of the Mn-doped systems are presented for a range of oxidation states and then complemented by calculations that highlight the role of electron-spin coupling between the Mn 3d states and electrons trapped at intrinsic vacancies such as surface F-centres. The strength of this spin-coupling is then used to help explain the interaction between a $\mathrm{CO}_{2}$ adsorbate and the $\mathrm{Mn}-\mathrm{MgO}(100)$ surface, both with and without F-centres.

\section{Computational methodology}

Calculations were performed using the hybrid quantum mechanical and molecular mechanical (QM/MM) embedded-cluster methodology that has previously proven to be accurate in modelling the bulk and surface chemistry of $\mathrm{MgO} .^{8,34-43}$ Our chosen $\mathrm{QM} / \mathrm{MM}$ implementation is the software environment ChemShell, ${ }^{44-46}$ with QM and MM energy evaluations performed with the NWChem ${ }^{47}$ and GULP ${ }^{48-50}$ software packages, respectively, and geometry optimisation was performed using the DL-FIND software routines. ${ }^{45}$

For the QM calculations, density functional theory (DFT) was used with the B3LYP ${ }^{51-53}$ and $\mathrm{B} 97-3^{54}$ exchange-correlation (XC) functionals. Results obtained using B3LYP provide a direct comparison with previous work for $\mathrm{MgO},{ }^{42}$ while $\mathrm{B} 97-3$ provides comparison with an XC functional that was fitted to a more extensive set of molecular thermochemical data. A Def2 triplezeta valence plus polarisation (TZVP) basis set ${ }^{55}$ was used for all atoms except Mn, where a Stuttgart/Dresden relativistic small-core effective core potential (ECP) was used with a complementing modified basis set: ${ }^{56}$ the most diffuse functions were removed to prevent the artificial spreading of charge density outside the QM region. Large core $\mathrm{ECP}^{57}$ for $\mathrm{Mg}^{2+}$ ions were placed on cations at the border of the QM region, representing the QM/MM boundary. The redox-active Mn dopant can adopt different energeticallycompetitive spin configurations, particularly when neighbouring an unpaired electron on an oxygen vacancy $\left(\mathrm{F}^{+}\right)$, and therefore the spin-states were explicitly checked. High-spin (HS) configurations were energetically favoured for defect-free systems, which preserves the unpaired $\mathrm{Mn} \mathrm{d}^{5}$ configuration in $\mathrm{Mn}-\mathrm{MgO}$ in agreement with previous calculations. ${ }^{26,28}$ For pure $\mathrm{MgO}$, a closed-shell configuration was always preferable. Unless otherwise stated, all calculations use these configurations.

The MM energy is calculated using a polarisable interatomic forcefield with Coulomb $\left(E_{\mathrm{MM}}^{\mathrm{Coul}}\right)$, Buckingham $\left(E_{\mathrm{MM}}^{\mathrm{Buck}}\right)$ and spring $\left(E_{\mathrm{MM}}^{\text {spring }}\right)$ terms that are defined as: ${ }^{49}$

$$
\begin{gathered}
E_{\mathrm{MM}, i j}^{\mathrm{Coul}}=\frac{q_{i} q_{j}}{r_{i j}} \\
E_{\mathrm{MM}, i j}^{\mathrm{Buck}}=A e^{\left(\frac{-r_{i j}}{\rho}\right)}-\frac{C_{6}}{r_{i j}{ }^{6}} \\
E_{\mathrm{MM}, i j}^{\mathrm{spring}}=\frac{1}{2} k_{2} r_{i j}{ }^{2}+\frac{1}{24} k_{4} r_{i j}{ }^{4}
\end{gathered}
$$

between two centres with indices $i$ and $j$, separated by a distance of $r_{i j}$. The parameters are the charge $(q$, in $e)$, the spring constants ( $k_{2}$ and $k_{4}$, in eV $\AA^{-2}$ and $\mathrm{eV} \AA^{-4}$, respectively) and the Buckingham potential parameters $A, \rho$ and $C$. The parameterisations we have used, which are presented in Table 1, are slightly modified versions of those derived by Lewis and Catlow: ${ }^{58}$ the cut-off radius has been extended from 6 to $12 \AA$ and the $\mathrm{O}_{\text {shell }}-\mathrm{O}_{\text {shell }}$ interaction tuned in order to reproduce accurately the dielectric constants of $\mathrm{MgO}$, with polarisable shells included on cations as well as anions. No additional potential terms were included to account for the interactions of the $\mathrm{CO}_{2}$ adsorbates with the surface as the closest MM atoms were at least $5 \AA$ away.

A spherical or hemispherical QM/MM cluster was used for bulk and surface models, respectively, with a total radius of $30 \AA$ centred on either an oxygen atom or vacancy. The central QM region contained a total of 33 atoms for the bulk and from 22 to 26 atoms for the surface (e.g. Fig. 2); this setup previously produced accurate results for $\mathrm{MgO} .{ }^{42}$ The radius of the active MM region was set to $15 \AA$ as atoms beyond this distance did not move during previous geometry optimisations. ${ }^{42}$ This partitioning meant that $\sim 1500(\sim 850)$ atoms underwent ionic relaxation in our bulk (slab) models, with atoms beyond $15 \AA$ fixed in their lattice positions. The lattice constant was obtained for MgO using GULP and the forcefield of choice. Once cut, 
Table 1 Forcefield parameters for the $\mathrm{Mn}-\mathrm{MgO}$ calculations. Coul. and Buck. are contractions for Coulomb and Buckingham, respectively. The parameters are the core charge $\left(q_{\text {core }}\right.$, in $\left.e\right)$, the shell charge $\left(q_{\text {shell }}\right.$, in $\left.e\right)$, the spring constants ( $k_{2}$ and $k_{4}$, in $\mathrm{eV} \AA^{-2}$ and $\mathrm{eV} \AA^{-4}$, respectively), the Buckingham potential parameters $A$ (in eV), $\rho$ (in $\AA$ ) and $C$, and the cutoff for the potential $\left(r_{\mathrm{c}}\right)$ in $\AA$

\begin{tabular}{|c|c|c|c|c|}
\hline Coul. \& spring & $q_{\text {core }}$ & $q_{\text {shell }}$ & $k_{2}$ & $k_{4}$ \\
\hline $\mathrm{Mg}$ & 0.415 & 1.585 & 361.60 & 0.0 \\
\hline Mn & -1.420 & 3.420 & 95.00 & 0.0 \\
\hline $\mathrm{O}$ & 1.000 & -3.000 & 54.76 & 0.0 \\
\hline Buck. & $A$ & $\rho$ & $C$ & $r_{\mathrm{c}}$ \\
\hline $\mathrm{Mg}_{\text {shell }}-\mathrm{O}_{\text {shell }}$ & 1428.5 & 0.2945 & 0.0 & 12.0 \\
\hline $\mathrm{Mn}_{\text {shell }}-\mathrm{O}_{\text {shell }}$ & 1007.4 & 0.3262 & 0.0 & 12.0 \\
\hline $\mathrm{O}_{\text {shell }}-\mathrm{O}_{\text {shell }}$ & 22764.3 & 0.1490 & 23.0 & 12.0 \\
\hline
\end{tabular}

the surface clusters were oriented so that the $x$ - and $y$-axes are in the plane of the surface, and the $z$-axis is perpendicular to the surface.

The total energy of the system is defined additively as:

$$
E_{\mathrm{Total}}=E_{\mathrm{QM}}+E_{\mathrm{MM}}+E_{\mathrm{Jost}}
$$

where $E_{\mathrm{MM}}$ and $E_{\mathrm{QM}}$ are the energies of the $\mathrm{MM}$ and $\mathrm{QM}$ regions, respectively, and $E_{\text {Jost }}$ is the Jost correction, necessary due to the finite size of the relaxed region of the QM/MM model when dealing with charged defects, thus incorporating long range effects through a dielectric medium term. For the bulk, $E_{\text {Jost }}$ is: ${ }^{59}$

$$
E_{\mathrm{Jost}}^{\mathrm{bulk}}=-\frac{Q^{2}}{2 R}\left(1-\frac{1}{\varepsilon}\right)
$$

where $Q$ denotes the total charge of any defect in the system, $R$ is the radius of the relaxed region in $a_{0}$ (Bohr units) and $\varepsilon$ is the dielectric constant of the material, which in this case is MgO. For a surface, $E_{\text {Jost }}$ is: ${ }^{59}$

$$
E_{\mathrm{Jost}}^{\mathrm{surf}}=-\frac{Q^{2}(\varepsilon-1)}{2 R(\varepsilon+1)} .
$$

We have used the static $\left(\varepsilon_{0}\right)$ and high-frequency $\left(\varepsilon_{\infty}\right)$ dielectric constants when calculating $E_{\text {Jost }}$ for adiabatic and instantaneous processes, respectively. The MM forcefield was used to calculate $\varepsilon_{0}(9.7033)$ and $\varepsilon_{\infty}(3.01584)$, with both values matching closely the available experimental literature for static $(9.65,9.8)$ and optical (2.95) dielectric constants. ${ }^{60}$

\section{$3 \mathrm{Mn}$-doped $\mathrm{MgO}$ bulk}

In order to test and validate our QM/MM model, we calculated the energy required to replace $\mathrm{Mg}$ with an $\mathrm{Mn}$ atom in $\mathrm{MgO}$. The reaction scheme of this substitution is:

$$
\mathrm{MgO}(\mathrm{s})+\mathrm{Mn}(\mathrm{ref}) \rightarrow \mathrm{Mn}-\mathrm{MgO}(\mathrm{s})+\mathrm{Mg}(\mathrm{ref}),
$$

where (ref) indicates a reference state. Thus, the formation energy, $E_{\mathrm{f}}(\mathrm{Mn}-\mathrm{MgO})$, can be written as:

$$
E_{\mathrm{f}}(\mathrm{Mn}-\mathrm{MgO})=E(\mathrm{Mn}-\mathrm{MgO})-E(\mathrm{MgO})+E(\mathrm{Mg})-E(\mathrm{Mn})+q \varepsilon_{\mathrm{f}},
$$

where $E(\mathrm{Mn}-\mathrm{MgO}), E(\mathrm{MgO}), E(\mathrm{Mg})$ and $E(\mathrm{Mn})$ are the energy of the doped $\mathrm{Mn}-\mathrm{MgO}$, pristine $\mathrm{MgO}, \mathrm{Mg}$ reference and $\mathrm{Mn}$ reference, respectively, and the charge of non-isovalent systems are accounted through the inclusion of the final $q \varepsilon_{\mathrm{f}}$ term, where $q$ is the formal charge of the defect, i.e. $\mathrm{Mn}^{(2+q)+}$, and $\varepsilon_{\mathrm{f}}$ is the Fermi level of the system. An alternative charge compensation is provided by cationic vacancies, ${ }^{61,62}$ which we have considered as doubly-charged $\mathrm{Mg}$ vacancies $\left(V_{\mathrm{Mg}}^{\prime \prime}\right)$ formed as:

$$
\mathrm{Mg}_{\mathrm{Mg}}^{\times} \rightarrow V_{\mathrm{Mg}}^{\prime \prime}+\mathrm{Mg}_{\mathrm{at}}^{\bullet \bullet}
$$

Considering our Mn-doped systems, $\mathrm{Mg}_{\mathrm{at}}^{\bullet \bullet}$ can be replaced with $\mathrm{Mg}_{\text {at }}^{\times}$with the corresponding holes instead localised on the extrinsic defects, with substitution of the formation energy for the $\mathrm{Mg}$ vacancy in the place of $\varepsilon_{\mathrm{f}}$ in eqn (10) giving:

$$
\begin{aligned}
E_{\mathrm{f}}(\mathrm{Mn}-\mathrm{MgO})= & E(\mathrm{Mn}-\mathrm{MgO})-E(\mathrm{MgO})+E(\mathrm{Mg}) \\
& -E(\mathrm{Mn})+\frac{q}{2}\left\{E\left(\mathrm{Mg}_{\mathrm{at}}^{\times}\right)+E\left(V_{\mathrm{Mg}}^{\prime \prime}\right)-E(\mathrm{MgO})\right\},
\end{aligned}
$$

where $q$ is again the formal charge of the $\mathrm{Mn}$-dopant in $\mathrm{MgO}$ and a factor of $\frac{1}{2}$ appears due to the double charge on the $\mathrm{Mg}$ vacancy. In all cases, the energy of the $\mathrm{Mg}$ reference state is:

$$
E(\mathrm{Mg})=E\left(\mathrm{Mg}_{\mathrm{at}}\right)+\mu(\mathrm{Mg}),
$$

where $E\left(\mathrm{Mg}_{\text {at }}\right)$ is the calculated energy of the gas-phase atom and $\mu(\mathrm{Mg})$ is the chemical potential of $\mathrm{Mg}$, with $E(\mathrm{Mn})$ calculated similarly. $E\left(\mathrm{Mg}_{\mathrm{at}}\right)$ and $E\left(\mathrm{Mn}_{\mathrm{at}}\right)$ were calculated as $E\left(\mathrm{Mg}_{\mathrm{at}}{ }^{2+}\right)$ and $E\left(\mathrm{Mn}_{\mathrm{at}}{ }^{2+}\right)$ minus the respective 1 st and 2 nd experimental ionisation energies for each element, as successfully applied previously for embedded-cluster calculations with modified basis sets. ${ }^{63}$ $\mu(\mathrm{Mg})$ and $\mu(\mathrm{Mn})$ were derived using a Born-Haber cycle and literature values for energetic processes. ${ }^{64}$

$\mathrm{Mg}(\mathrm{s})$ and $\mathrm{Mn}(\mathrm{s})$ are the reference states at low oxygen partial pressure, $p\left(\mathrm{O}_{2}\right)$, and thus their vaporisation enthalpies of 143.38 and $279.58 \mathrm{~kJ} \mathrm{~mol}^{-1}$ are used to derive $\mu(\mathrm{Mg})-\mu(\mathrm{Mn})=$ $136.2 \mathrm{~kJ} \mathrm{~mol}^{-1}(1.41 \mathrm{eV})$. In a physical sense, a positive value means the stronger bonding in the $\mathrm{Mn}(\mathrm{s})$ reactant would inhibit the reaction. In contrast, for high $p\left(\mathrm{O}_{2}\right)$ the reference states are $\mathrm{MgO}(\mathrm{s})$ and $\mathrm{MnO}(\mathrm{s})$, respectively. In this case, the formation enthalpy for $\mathrm{MgO}\left(-601.6 \mathrm{~kJ} \mathrm{~mol}^{-1}\right)$ and $\mathrm{MnO}\left(-385.2 \mathrm{~kJ} \mathrm{~mol}^{-1}\right)$ are combined with the values above to give $\mu(\mathrm{Mg})-\mu(\mathrm{Mn})=$ $-80.2 \mathrm{~kJ} \mathrm{~mol}^{-1}(-0.83 \mathrm{eV})$, with the negative value indicating favourability for the $\mathrm{MgO}$ product over the MnO reactant.

Our results for isovalent $E_{\mathrm{f}}^{\text {bulk }}(\mathrm{Mn}-\mathrm{MgO})$ are presented in Table 2. The formation of Mn-dopants at low and high $p\left(\mathrm{O}_{2}\right)$ are endothermic, with energies of 2.73(2.55) and $0.49(0.31) \mathrm{eV}$, respectively, for the B3LYP(B97-3) XC functional. Our high $p\left(\mathrm{O}_{2}\right)$ results match previous work by Konigstein et al. and Heath et al. for the enthalpies of mixing $\left(\Delta H_{\text {mix }}\right)$ of $\mathrm{MgO}$ and MnO: $12.5 \% \mathrm{MnO}$ in $\mathrm{MgO}$ was found to be endothermic by 0.03 and $0.05-0.06 \mathrm{eV}$ at the GULP and Hartree-Fock levels of theory, respectively, ${ }^{22,24}$ in good agreement with experiment $(0.02 \mathrm{eV}) .{ }^{23}$ We consider that $\Delta H_{\text {mix }}(\mathrm{MgO} / \mathrm{MnO})$ is lower than for our results due to the relaxation of the bulk lattice constants 
Table $2 E_{f}(\mathrm{Mn}-\mathrm{MgO})$, in $\mathrm{eV}$, for isovalent bulk $\left(\mathrm{Mn}_{\text {bulk }}\right)$, surface $\left(\mathrm{Mn}_{\text {surf }}\right)$ and subsurface $\left(\mathrm{Mn}_{\text {sub }}\right)$ sites as calculated for environments with low (high) $p\left(\mathrm{O}_{2}\right)$ with the B3LYP and B97-3 XC functionals. For reference, $E_{\mathrm{f}}(\mathrm{Mn}-\mathrm{MgO})$ for an $\mathrm{Mn}$-dopant in an infinitely dilute $\mathrm{MgO}$ environment at high $p\left(\mathrm{O}_{2}\right)$, as calculated using the presented MM forcefields, is also given. For $E_{\mathrm{f}}(\mathrm{Mn}-\mathrm{MgO})$ relative to the gas phase atoms, one can subtract $\mu(\mathrm{Mg})-\mu(\mathrm{Mn})$ from these values. A HS configuration (sextuplet multiplicity) was energetically preferred for $\mathrm{Mn}-\mathrm{MgO}$ in all DFT calculations

\begin{tabular}{lllr}
\hline & B3LYP & B97-3 & \multicolumn{1}{l}{ MM } \\
\hline $\mathrm{Mn}_{\text {bulk }}$ & $2.73(0.49)$ & $2.55(0.31)$ & $-(0.23)$ \\
$\mathrm{Mn}_{\text {sub }}$ & $2.67(0.43)$ & $2.53(0.28)$ & $-(0.23)$ \\
$\mathrm{Mn}_{\text {surf }}$ & $2.16(-0.08)$ & $2.00(-0.24)$ & $-(-0.35)$ \\
$5.354(516.566)$ & & &
\end{tabular}

in this previous work; ${ }^{22}$ an effect that is not included in our calculations. Interestingly, all of these results are contrary to the Mn-doping DFT calculations of Panigrahi et al. ${ }^{30}$ where results using the generalised-gradient approximation ${ }^{65}$ give $E_{\mathrm{f}}^{\mathrm{bulk}}(\mathrm{Mn}-\mathrm{MgO})=$ $-0.1 \mathrm{eV}$ for a 64-atom unit cell, relative to atomic reference states, and adjustment for a high $p\left(\mathrm{O}_{2}\right)$ environment gives $E_{\mathrm{f}}(\mathrm{Mn}-\mathrm{MgO})=$ $-0.93 \mathrm{eV}$, which is surprisingly exothermic.
Structural analysis of the B3LYP calculation shows that the Mn-O bond length in the doped system is $2.18 \AA$, which is an extension of the $\mathrm{Mg}-\mathrm{O}$ bond length $(2.12 \AA)$; identical extension of the metal-oxygen bond occurs when the XC is B97-3. Our results are in broad agreement with experimental lattice parameters for $\mathrm{MgO}(2.11 \AA)$ and $\mathrm{MnO}(2.22 \AA),{ }^{64}$ and with previous computational reports for isolated $\mathrm{Mn}$ dopants in $\mathrm{MgO}$, which give an $\mathrm{Mn}-\mathrm{O}$ bond distance of $\sim 2.1 \AA^{30}{ }^{30}$

Fig. 1 illustrates the formation energy for $\mathrm{Mn}$ dopants of differing charge states in $\mathrm{MgO}$, in the range $0 \leq q \leq 5$, within the limits of $\varepsilon_{\mathrm{f}}$. This graph can be considered as a guide to the favoured oxidation state of an Mn-dopant in either $\mathrm{p}$ - or n-type conditions. The lower bound for $\varepsilon_{\mathrm{f}}$ is the valence band maximum (VBM), which we position as the negative of the vertical ionisation potential (VIP) for MgO. QM/MM allows us to calculate the VIP for MgO as 6.27(6.51) eV for the B3LYP(B97-3) XC functional using the $\Delta$ SCF technique, ${ }^{66}$ which is a slight underestimate of experiment $(7.16 \mathrm{eV})^{67}$ and lower than our previous estimates using XC functionals tuned for bulk materials (PBE0: $6.89 \mathrm{eV}$; PBESol0: $6.97 \mathrm{eV}) .{ }^{6}$ The upper bound for $\varepsilon_{\mathrm{f}}$ would typically be the conduction band minimum (CBM) but the
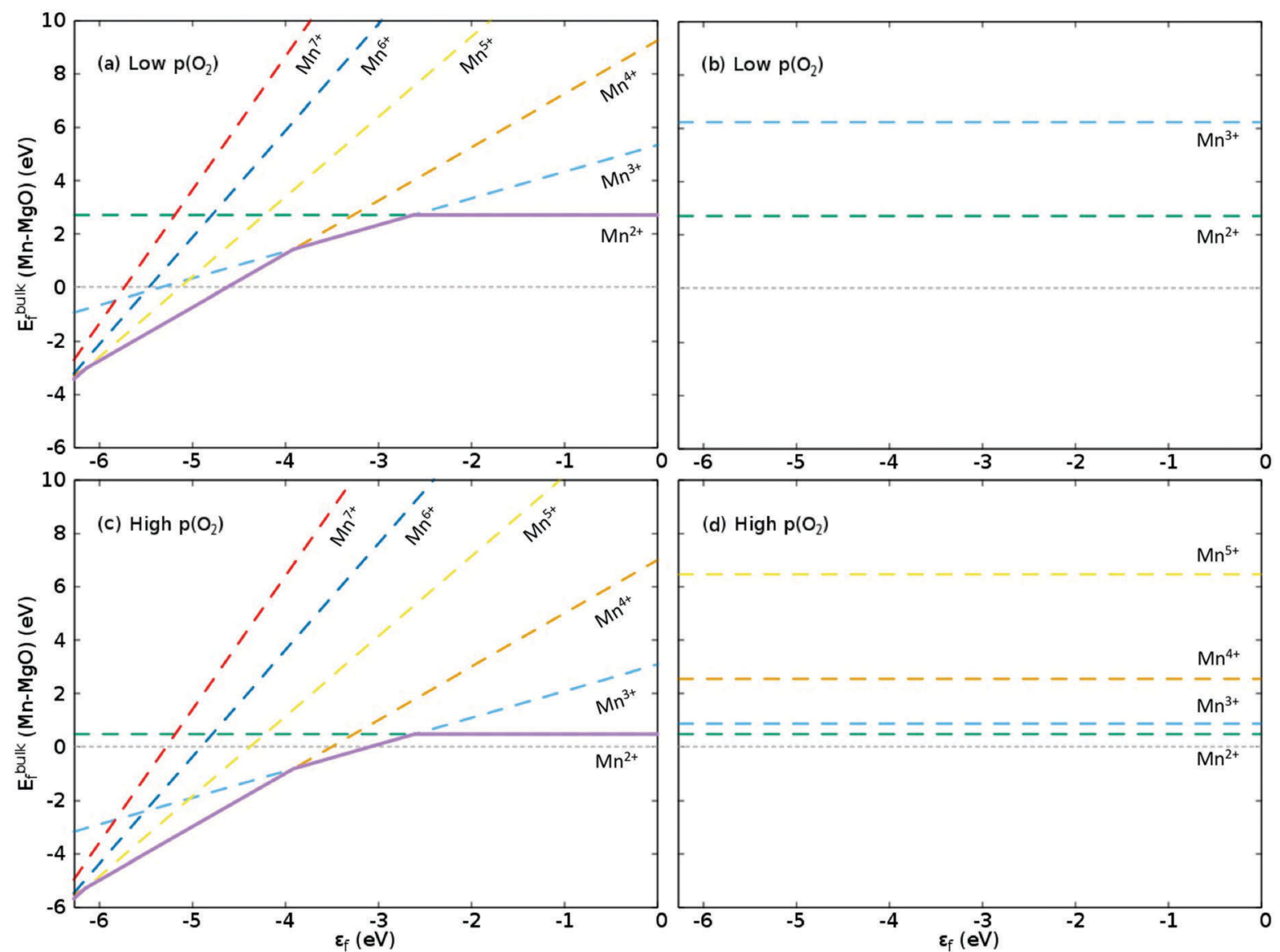

Fig. $1 E_{\mathrm{f}}$ for bulk Mn dopants in MgO when using the B3LYP XC functional at (a and b) low and (c and d) high $p\left(\mathrm{O}_{2}\right)$, with $\varepsilon_{\mathrm{f}}$ ranging from the VBM (-6.27 eV) through to vacuum level $(0 \mathrm{eV})$. (a and c) Show $E_{\mathrm{f}}$ as compensated by electrons transferring to the Fermi level, $\varepsilon_{\mathrm{f}}$, as calculated with eqn $(10)$ whilst $(\mathrm{b})$ and (d) show $E_{\mathrm{f}}$ as compensated by cation ( $\mathrm{Mg}$ ) vacancies (eqn (12)). Dashed green, aqua, gold, yellow, navy blue and red lines show $E_{\mathrm{f}}$ when the defect charge

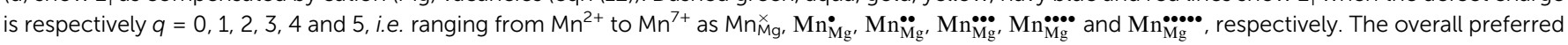
defect charge as a function of $\varepsilon_{\mathrm{f}}$, which is found to be compensated by the Fermi level in all cases, is given as a solid purple line in (a) and (c). 
band gap of $\mathrm{MgO}(7.83 \mathrm{eV})^{68}$ is greater than the VIP, which means the conduction band is actually above the vacuum level. As electrons would not favour going into a CBM with a positive energy, the vacuum level $(0 \mathrm{eV})$ becomes the upper bound for $\varepsilon_{\mathrm{f}}$. Comparison of the Mulliken analysis for the bulk $\mathrm{MgO}$ and $[\mathrm{MgO}]^{+}$models shows that the electrons are ionised from the $2 \mathrm{p}$ states of the central oxygen, though the remaining electron hole is delocalised over neighbouring atoms as also previously documented for MgO surfaces. ${ }^{35}$ In addition to these observations, we also calculated the 1st and 2nd VIPs for $\mathrm{Mn}_{\text {bulk }}-\mathrm{MgO}$ to be $4.27(4.38)$ and $5.62(5.86) \mathrm{eV}$, respectively, which means that the highest occupied Mn $3 \mathrm{~d}$ states are positioned in the bandgap, in agreement with previous reports. ${ }^{25-27}$ For higher order VIPs, the Mn 3d states hybridise with the $\mathrm{O} 2 \mathrm{p}$ states in the energy range of -8 to $-11 \mathrm{eV}$ to form ill-defined resonance states.

The graphs for Fermi level-compensated Mn-dopants in (a) low and (c) high $p\left(\mathrm{O}_{2}\right)$ in Fig. 1 are clear translations of each other, with both showing that a like-for-like replacement of $\mathrm{Mg}$ with $\mathrm{Mn}$ is preferred when $\varepsilon_{\mathrm{f}}$ is close to $0 \mathrm{eV}$. Reducing $\varepsilon_{\mathrm{f}}$ results in a shift towards higher oxidation states, which may be attributed to the stability of $\mathrm{Mn}$ in $3+, 4+$ and $5+$ oxidation states; in experiment the position of $\varepsilon_{\mathrm{f}}$ would be strongly dependent on factors such as the dopant concentration. For low $p\left(\mathrm{O}_{2}\right), E_{\mathrm{f}}$ for $\mathrm{Mn}^{4+}$ is exothermic below $\varepsilon_{\mathrm{f}}=-4.63 \mathrm{eV}$, and for high $p\left(\mathrm{O}_{2}\right)$ the formation of $\mathrm{Mn}^{3+}$ and $\mathrm{Mn}^{4+}$ is exothermic below $\varepsilon_{\mathrm{f}}=-3.10$ and $-3.51 \mathrm{eV}$, respectively, with formation of higher oxidation states also exothermic at lower $\varepsilon_{\mathrm{f}}$ in both cases: $\mathrm{Mn}^{5+}$ is the most favourable dopant state in both environments in the range of $\varepsilon_{\mathrm{f}}$ from -6.13 to $-6.27 \mathrm{eV}$. We note from graphs (b) and (d) in Fig. 1, and Table 3 , that using $\mathrm{Mg}$ vacancies as compensating defects results in higher formation energies than using electron compensation, though the $\mathrm{Mn}^{3+}$ defect is competitive with the isovalent defect at high $p\left(\mathrm{O}_{2}\right)$, differing by $0.38 \mathrm{eV}$. This observation is general to our calculations for B3LYP and B97-3, as shown in Table 3, with only the former plotted in Fig. 1 and discussed in detail here: the difference in $E_{\mathrm{f}}$ for isovalent $(2+)$ and $3+$ Mn-dopants when using the latter $\mathrm{XC}$ functional is also $0.38 \mathrm{eV}$.

In general, it is noted that Mn-doping is exothermic in p-type conditions, both at low and high $p\left(\mathrm{O}_{2}\right)$. As the dopant concentration increases the material will become more n-type due to the presence of Mn-defect states in the band gap, resulting in changes to the most stable Mn oxidation state: at $\varepsilon_{\mathrm{f}}=-4.27(-4.38) \mathrm{eV}$, $\mathrm{Mn}^{4+}$ is thermodynamically favoured. Lower oxidation states, such as isovalent $\mathrm{Mn}^{2+}$, are endothermic in formation and would require n-type conditions during synthesis. Typically, n-type conditions are achieved by using low $p\left(\mathrm{O}_{2}\right)$, which results in oxygen vacancies with defect states high in the band gap, as discussed later; surface oxygen vacancies are also of interest for catalytic purposes, where the F-centres can play an important role in reactivity. Therefore, the material properties could be tuned with careful synthesis protocols.

Due to the similarity of our results thus far for the different XC functionals, only those acquired using the B3LYP XC functional will be discussed subsequently unless explicitly stated.
Table $3 E_{f}(M n-M g O)$, in $\mathrm{eV}$, for bulk $\left(\mathrm{Mn}_{\text {bulk }}\right)$, surface $\left(\mathrm{Mn}_{\text {surf }}\right)$ and subsurface $\left(\mathrm{Mn}_{\text {sub }}\right)$ sites as calculated with the B3LYP(B97-3) XC functional at high $p\left(\mathrm{O}_{2}\right)$ for varying charge $(q)$ and position of $\varepsilon_{f}$, with the latter ranging between vacuum $(0 \mathrm{eV})$ and the valence band maximum (VBM). Values of $q$ marked with ${ }^{a}$ have been compensated by cation vacancies (eqn (12)), with all other values compensated by the use of the Fermi level (eqn (10))

\begin{tabular}{llrrrr}
\hline & $q$ & $\varepsilon_{\mathrm{f}}=0 \mathrm{eV}$ & & $\varepsilon_{\mathrm{f}}=\mathrm{VBM}$ & \\
\hline $\mathrm{Mn}_{\text {bulk }}$ & 0 & 0.49 & $(0.31)$ & 0.49 & $(0.31)$ \\
& 1 & 3.10 & $(3.11)$ & -3.18 & $(-3.40)$ \\
& 2 & 7.01 & $(7.23)$ & -5.53 & $(-5.79)$ \\
& 3 & 13.15 & $(13.49)$ & -5.67 & $(-6.03)$ \\
& $1^{a}$ & 0.87 & $(0.68)$ & 0.87 & $(0.68)$ \\
& $2^{a}$ & 2.55 & $(2.37)$ & 2.55 & $(2.37)$ \\
& $3^{a}$ & 6.45 & $(6.20)$ & 6.45 & $(6.20)$ \\
& & & & & \\
$\mathrm{Mn}_{\text {sub }}$ & 0 & 0.43 & $(0.28)$ & 0.43 & $(0.28)$ \\
& 1 & 3.00 & $(3.00)$ & -3.15 & $(-3.40)$ \\
& 2 & 7.13 & $(7.37)$ & -5.17 & $(-5.42)$ \\
& 3 & 13.67 & $(13.95)$ & -4.78 & $(-5.23)$ \\
& $1^{a}$ & 0.76 & $(0.58)$ & 0.76 & $(0.58)$ \\
& $2^{a}$ & 2.67 & $(2.50)$ & 2.67 & $(2.50)$ \\
& $3^{a}$ & 6.98 & $(6.65)$ & 6.98 & $(6.65)$ \\
$\mathrm{Mn}_{\text {surf }}$ & & & & & \\
& 0 & -0.08 & $(-0.24)$ & -0.08 & $(-0.24)$ \\
& 1 & 2.54 & $(2.56)$ & -3.60 & $(-3.83)$ \\
& 2 & 7.54 & $(7.72)$ & -4.76 & $(-5.06)$ \\
& 3 & 14.16 & $(14.32)$ & -4.29 & $(-4.85)$ \\
& $1^{a}$ & 0.31 & $(0.13)$ & 0.31 & $(0.13)$ \\
& $2^{a}$ & 3.08 & $(2.86)$ & 3.08 & $(2.86)$ \\
& $3^{a}$ & 7.46 & $(7.03)$ & 7.46 & $(7.03)$ \\
& & & & & \\
\hline
\end{tabular}

\section{Mn-doped $\mathrm{MgO}(100)$ surface}

\subsection{Position of Mn-dopant}

As illustrated in Fig. 2, two different QM/MM clusters were used for the Mn-MgO surfaces: (a) the Mn dopant positioned in the surface layer (Layer 1, L1), adjacent to the central oxygen; (b) the Mn dopant situated in the first subsurface layer (Layer 2, L2), directly beneath the central oxygen. Henceforth, these two configurations will be referred to as $\mathrm{Mn}_{\text {surf }}$ and $\mathrm{Mn}_{\text {sub }}$, respectively. The Cartesian axes of the QM/MM cluster have been defined so that the $x y$-plane aligns with the surface-plane of the model; thus $\mathrm{Mn}_{\text {sub }}$ occupies the $\mathrm{Mg}$ lattice position $(0,0, z)$ and $\mathrm{Mn}_{\text {surf }}$ occupies the $\mathrm{Mg}$ lattice position $(x, 0,0)$, with the primary oxygen lattice site $\left(\mathrm{O}_{5 \mathrm{c}}\right.$ or F-centre $)$ at $(0,0,0)$.

Our results, which are presented in Tables 2 and 3, show that formation of isovalent Mn-doped surface layers is exothermic at high $p\left(\mathrm{O}_{2}\right)$ when compensated using $\varepsilon_{\mathrm{f}}$, whereas formation of subsurface dopants is very similar to bulk behaviour, being endothermic for all $p\left(\mathrm{O}_{2}\right)$. With reduction of $\varepsilon_{\mathrm{f}}$ from $0 \mathrm{eV}$ towards the VBM, higher oxidation states become preferable with $\mathrm{Mn}^{4+}$ the most stable at $\varepsilon_{\mathrm{f}}=$ VBM. In contrast, cation-vacancy compensated defects remain endothermic (Table 3). Overall, $\mathrm{Mn}_{\text {surf }}$ is energetically favoured over $\mathrm{Mn}_{\text {sub }}$ (and $\mathrm{Mn}_{\text {bulk }}$ ) for $q=0$ and 1 as the electronic and structural flexibility of the surface minimises any strain induced by the discrepancy in radius between $\mathrm{Mn}$ and $\mathrm{Mg}$ (0.83 vs. $0.72 \AA$ for $2+$ cations, respectively). ${ }^{69}$ In addition, at these charge states $E_{\mathrm{f}}\left(\mathrm{Mn}_{\text {surf }}\right)<E_{\mathrm{f}}\left(\mathrm{Mn}_{\text {bulk }}\right)$, whereas $E_{\mathrm{f}}\left(\mathrm{Mn}_{\text {sub }}\right) \approx E_{\mathrm{f}}\left(\mathrm{Mn}_{\text {bulk }}\right)$. We note that low-spin (LS) $\mathrm{Mn}^{2+}$ is in fact structurally smaller $(0.67 \AA)$ than $\mathrm{HS} \mathrm{Mn}^{2+}, 69$ in octahedral coordination, but a half-filled d-shell with no degenerate 


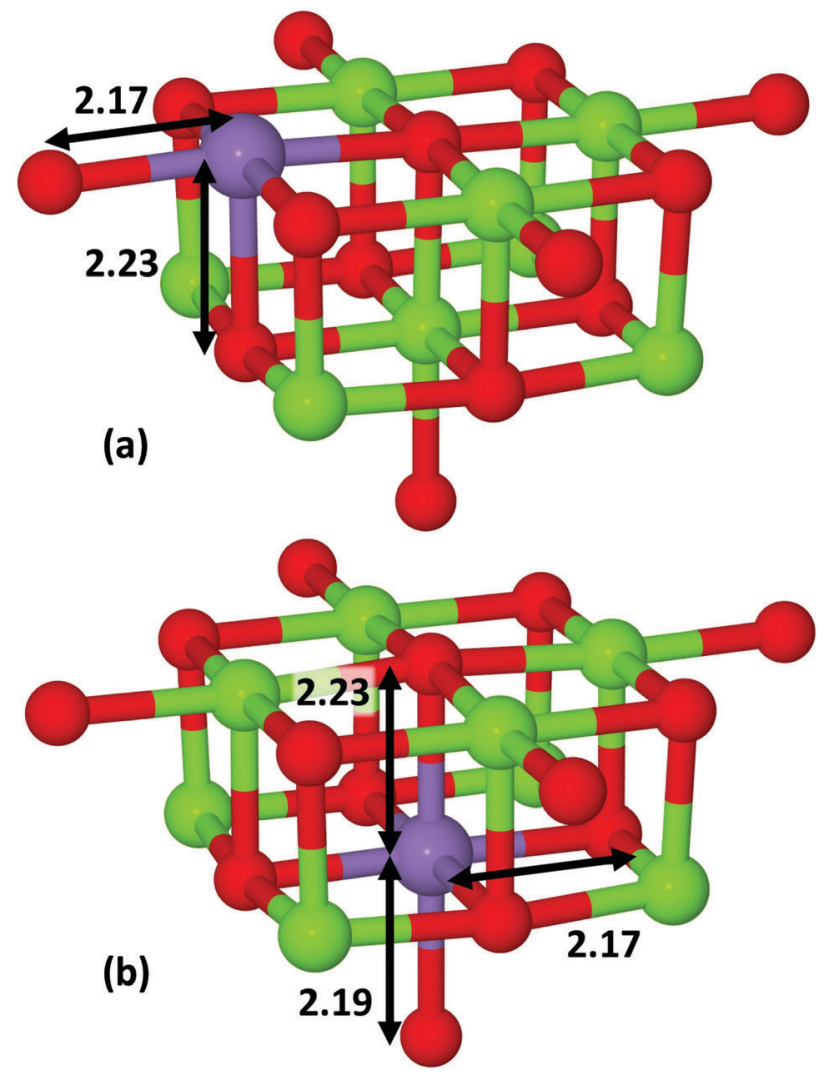

Fig. 2 QM cluster illustrating the $M n$-dopant in (a) surface $\left(M n_{\text {surf }}\right)$ and (b) subsurface $\left(\mathrm{Mn}_{\text {sub }}\right)$ positions. $\mathrm{O}$ atoms are shown in red, $\mathrm{Mg}$ in green and $\mathrm{Mn}$ in purple. Bond lengths are given in $\AA$.

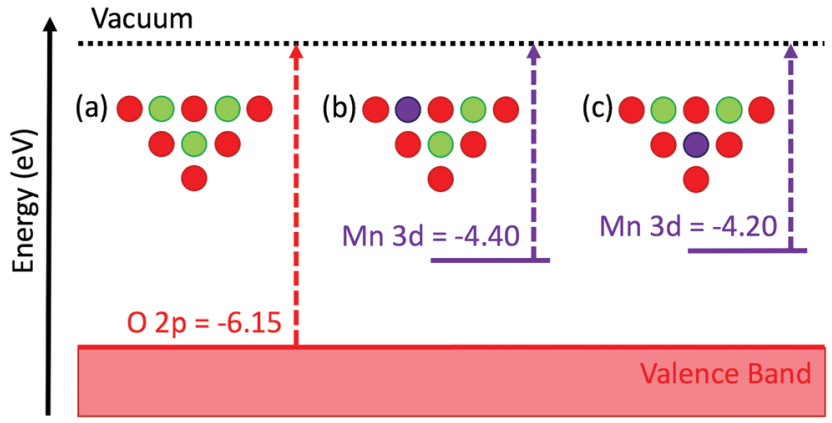

Fig. 3 Position of the surface valence band and defect states, relative to vacuum, for (a) MgO; (b) $\mathrm{Mn}_{\text {surf }}-\mathrm{MgO}$; and (c) $\mathrm{Mn}_{\text {sub }}-\mathrm{MgO}(100)$ surfaces. Red, green and purple circles represent $\mathrm{O}, \mathrm{Mg}$ and $\mathrm{Mn}$ atoms, respectively. The colour scheme of the electronic transitions matches the origin of electrons for the vertical ionisation potential (VIP): the valence band is $O 2 p$ states and $M n 3 d$ defect states are positioned in the band gap. The energies presented are calculated with the B3LYP XC functional, and the adiabatic ionisation potential (AIP) was calculated as 5.21, 2.62 and $2.56 \mathrm{eV}$ for models (a), (b) and (c), respectively.

occupancy ( $\mathrm{HS} \mathrm{d}^{5}$ ) is energetically preferable, which also means no Jahn-Teller distortion is observed, in agreement with previous calculations. ${ }^{30}$ For $q>1$, it is apparent that long-distance bulk electrostatics are more important, with $\mathrm{Mn}^{5+}$ unstable with respect to $\mathrm{Mn}^{4+}$ at the surface and sub-surface, yet preferred in the bulk.
On the un-doped $\mathrm{MgO}(100)$ surface, the $\mathrm{Mg}-\mathrm{O}$ bond lengths are $2.12 \AA$ in the $x y$-plane and the $z$-direction (L1 to L2). These bonds extend to 2.17 and $2.23 \AA$, respectively, for isovalent $\mathrm{Mn}_{\text {surf }}$ and the $\mathrm{O}-\mathrm{Mn}_{\text {surf }} \mathrm{O}$ bond angles are $90.0^{\circ}$ in the $x y$-plane but as low as $88.5^{\circ}$ and $87.3^{\circ}$ in the $x z$ - and $y z$-planes, respectively. The same bond angles are $91.6^{\circ}$ for $\mathrm{O}-\mathrm{Mg}-\mathrm{O}$, showing that the Mn dopants protrude outwards from the (100) surface whereas $\mathrm{Mg}$ withdraws inwards. For isovalent $\mathrm{Mn}_{\text {sub }}, \mathrm{Mn}-\mathrm{O}$ bond lengths are similarly extended to $2.17 \AA$ in the $x y$-plane (L2-L2) and 2.22(2.19) $\AA$ in the $z$-direction between L1 and L2 (L2 and Layer 3, L3), which is partly due to the relaxation of the surface oxygen atom outwards from the surface. ${ }^{7}$ For comparison, the same bonds for $\mathrm{Mg}-\mathrm{O}$ in the pure surface are 2.18 and $2.07 \AA$ for L1-L2 and L2-L3 interactions, which shows that the subsurface bond lengths increase by $>0.1 \AA$ due to the $\mathrm{Mn}_{\text {sub-dopant. The }}$ $\mathrm{O}-\mathrm{Mn}_{\text {sub }}-\mathrm{O}$ bond angles within the $x y$-plane were maintained at $90.0^{\circ}$, similar to $\mathrm{Mn}_{\text {surf }}$, whilst the elongation of the bonds in the $z$-direction, and upwards movement of $\mathrm{Mn}_{\text {sub }}$, creates bond angles of up to $90.6^{\circ}$ in the $x z$ - and $y z$-planes between the L1 and L2 oxygens.

In order to place the VBM for the surface, as well as to ascertain which atoms contribute to the band edges and dopant states, we calculated the VIP and the adiabatic ionisation potential (AIP) of the pure and Mn-doped $\mathrm{MgO}(100)$ surfaces (Fig. 3). For the MgO surface a VIP of 6.15(6.39) eV is calculated with the B3LYP(B97-3) XC functional, which is in fair agreement with experiment $(6.7 \pm 0.4 \mathrm{eV})^{70}$ though slightly lower than previous results from periodic DFT using XC functionals for bulk materials (6.52-6.57 eV) ${ }^{7}$ and QM/MM calculations with the B3LYP XC functional $(6.46, \sim 6.5 \mathrm{eV}){ }^{35,42}$ We attribute this difference to the incomparable XC potentials used in the previous periodic $\mathrm{DFT}^{7}$ the improvements in the MM forcefield and basis sets when compared to our own prior work, ${ }^{42}$ and an absence of long-range corrections $\left(E_{\text {Jost }}\right)$ in the work of Sushko et al. $;{ }^{35}$ if we remove $E_{\text {Jost }}$ from our calculations to match the latter work, the agreement between results improves with our VIP becoming 6.39(6.63) eV for the B3LYP(B97-3) XC functional. In all cases, Mulliken analysis shows that the electron removed during ionisation is taken from the surface oxygen atoms, which associates the VBM with $\mathrm{O} 2 \mathrm{p}$ states, in agreement with welldeveloped theories of metal oxide band structures. ${ }^{71,72}$ We also calculated the AIP of $\mathrm{MgO}(100)$ to be $5.21(5.23) \mathrm{eV}$, for the B3LYP(B97-3) XC functional, i.e. the relaxation of the nuclei around an electronic defect lowers the energy of the system by $0.94(1.16) \mathrm{eV}$. The smaller VIP of the MgO surface when compared to bulk $\mathrm{MgO}$ is due to surface band bending, as we have discussed previously elsewhere. ${ }^{7}$

The VIP for $\mathrm{Mn}_{\text {surf }}$ - and $\mathrm{Mn}_{\text {sub }}-\mathrm{MgO}$ is calculated as 6.16(6.41) and 6.14(6.32) eV, respectively, when using the B3LYP(B97-3) XC functional with a septuplet multiplicity i.e. an ionised electron is removed from the $\mathrm{O} 2 \mathrm{p}$ orbitals, with the HS $\mathrm{Mn} \mathrm{d}^{5}$ configuration preserved. Unsurprisingly, these results match the VIP for the pure MgO surface, reported above, as the O 2p states contribute to the VBM. However, changing our setup to an intermediate quintet spin-configuration, with the ionised electron removed instead from the Mn 3d states to give an 
$\mathrm{Mn} \mathrm{d}^{4}$ electronic configuration, the VIP is 4.40(4.63) and 4.20(4.32) eV for the same dopant systems and XC functionals, respectively (Fig. 3). The smaller VIP indicates that the highest occupied Mn 3d states are 1.76-1.94 eV above the O 2p states and thus in the band gap, matching the bulk systems (Section 3); the VIP of $\mathrm{Mn}_{\text {sub }}-\mathrm{MgO}$ is noted as being similar to the bulk, for which the VIP was calculated as $4.27(4.38) \mathrm{eV}$. Mulliken analysis further confirms that the electrons are removed from the Mn $3 \mathrm{~d}$ and $\mathrm{O} 2 \mathrm{p}$ orbitals on ionisation calculated with multiplicities of 5 and 7, respectively. Full localisation of the remaining holes is not achieved with 0.55 and 0.2 e removed from the $\mathrm{Mn}$ and central $\mathrm{O}$ in each respective calculation; however the hole does fully localise on the Mn dopant after geometry relaxation of the HS configuration. The AIP for the intermediate spin-state (IS) was calculated for $\mathrm{Mn}_{\text {surf }}{ }^{-}$and $\mathrm{Mn}_{\text {sub }}-\mathrm{MgO}$ as 2.62(2.81) and 2.56(2.71) eV, respectively, using the B3LYP(B97-3) XC functional; the energetic relaxation of the nuclei, and localisation of the hole, results in significant stabilisation by 1.61-1.83 eV. In addition, higher-order 2nd and 3rd VIPs were calculated for $\mathrm{Mn}_{\text {surf }}$ and $\mathrm{Mn}_{\text {sub }}-\mathrm{MgO}$ : the results for $\mathrm{Mn}_{\text {sub }}-\mathrm{MgO}$ match those of $\mathrm{Mn}_{\text {bulk }}$ with the 2nd $\mathrm{Mn}$ 3d state at $-6.02 \mathrm{eV}$, just above the VBM, whilst the 3rd Mn $3 \mathrm{~d}$ state is in the valence band i.e. a resonance state. For $\mathrm{Mn}_{\text {surf }}-\mathrm{MgO}$, the 2nd $\mathrm{Mn} 3 \mathrm{~d}$ state is already in the valence band, showing that the surface strongly stabilises the $3 \mathrm{~d}$ states and indicating a reason for the improved stability of the Mn-dopant at the surface.

\subsection{Oxygen vacancy formation}

Oxygen vacancies that contain trapped electrons on the surface of a material, i.e. surface F-centres, ${ }^{8}$ have previously been postulated as active sites for the conversion of $\mathrm{CO}_{2}$ to $\mathrm{CH}_{3} \mathrm{OH}$ on metal oxides, e.g. $\mathrm{Cu} / \mathrm{ZnO} / \mathrm{Al}_{2} \mathrm{O}_{3} \cdot{ }^{46,73-77}$ As discussed in Section 3, the formation of such vacancies would require careful material preparation, however their presence would be beneficial for catalytic applications. Therefore, we have calculated the formation energies of oxygen vacancies at the $\mathrm{Mn}-\mathrm{MgO}(100)$ surface, as presented in Table 4 . The formation energy, $E_{\mathrm{f}}\left(\mathrm{F}^{q+}\right)$, was calculated relative to the energy of the Mn-doped surface, $E(\mathrm{Mn}-\mathrm{MgO})$, and half an oxygen dimer, $\frac{1}{2} E\left(\mathrm{O}_{2}\right)$ :

$$
E_{\mathrm{f}}\left(\mathrm{F}^{n+}\right)=E\left(\mathrm{~F}^{q+} \mathrm{Mn}-\mathrm{MgO}\right)-E(\mathrm{Mn}-\mathrm{MgO})+\frac{1}{2} E\left(\mathrm{O}_{2}\right)+q \varepsilon_{\mathrm{f}} .
$$

As in eqn (10), $\varepsilon_{\mathrm{f}}$ is a variable that can vary between an upper limit of vacuum $(0 \mathrm{eV})$ and a lower limit of the VBM, which we calculate as $-6.15(-6.39) \mathrm{eV}$ for the B3LYP(B97-3) XC functional (Section 4.1). We discuss only $\varepsilon_{\mathrm{f}}=0 \mathrm{eV}$ in the text unless otherwise stated, as this is typical for a low $p\left(\mathrm{O}_{2}\right)$ environment that would facilitate the formation of oxygen vacancies.

A closed-shell configuration is energetically favoured for a neutral $\mathrm{F}^{0}$-centre on the (100) surface, with both electrons occupying the oxygen vacancy, i.e. $\mathrm{V}_{\mathrm{O}}^{\times}$, and the $\mathrm{Mn}^{2+}$ ion maintaining an open-shell $\mathrm{d}^{5}$ valence configuration. We denote this as intermediate-spin (IS), as a high-spin (HS) configuration would unpair the vacancy electrons and low-spin (LS) configuration would have the $\mathrm{Mn} \mathrm{d}^{5}$ electrons paired together, both of which are energetically unfavourable. For $\mathrm{Mn}_{\text {surf }}$ and $\mathrm{Mn}_{\text {sub }}-\mathrm{MgO}$, $E_{\mathrm{f}}\left(\mathrm{F}^{0}\right)$ is $6.14(5.85) \pm 0.02 \mathrm{eV}$ for the B3LYP(B97-3) XC functional, which is $\sim 0.4 \mathrm{eV}$ lower than that of the pure $\mathrm{MgO}(100)$ surface, ${ }^{42}$ as shown in Fig. 4.

In order to explore the effect of exchange coupling between the vacancy-trapped electrons and the Mn 3d-states for an $\mathrm{F}^{+}$-centre, we compare a parallel and anti-parallel alignment of the $\mathrm{V}_{\mathrm{O}}$ and $\mathrm{Mn} 3 \mathrm{~d}$ electrons. As can be seen in Table 4, IS (antiparallel) alignment gives $E_{\mathrm{f}}\left(\mathrm{F}^{+}\right)$of $7.64 \mathrm{eV}$ for $\mathrm{Mn}_{\text {surf }}$, with a very similar result for $\mathrm{Mn}_{\text {sub }}$, and $E_{\mathrm{f}}\left(\mathrm{F}^{+}\right)$is $\sim 0.27 \mathrm{eV}$ greater for the HS (parallel) configuration. The position of $\varepsilon_{\mathrm{f}}$ has significant effect on $E_{\mathrm{f}}\left(\mathrm{F}^{+}\right)$: when below $-1.48 \mathrm{eV}, E_{\mathrm{f}}\left(\mathrm{F}^{0}\right)>E_{\mathrm{f}}\left(\mathrm{F}^{+}\right)$for both Mn-doped surfaces. Additionally, $E_{\mathrm{f}}\left(\mathrm{F}^{+} \mathrm{Mn}-\mathrm{MgO}\right)$ is at least $0.35 \mathrm{eV}$ lower than $E_{\mathrm{f}}\left(\mathrm{F}^{+} \mathrm{MgO}\right)$, indicating that an Mn-dopant facilitates formation of an $\mathrm{F}^{+}$-centre (Fig. 4).

Ionisation of a second electron to form an $\mathrm{F}^{2+}$-centre could also be from the oxygen vacancy or the Mn dopant, which could potentially lead to doubly-charged (a) $\mathrm{Mn}_{\mathrm{Mg}}^{\bullet \bullet}$ or (b) $\mathrm{V}_{\mathrm{O}}^{\bullet \bullet}$ defects, or alternatively (c) sharing of the holes between both extrinsic and intrinsic defects, i.e.:

$$
\mathrm{V}_{\mathrm{O}}^{\times}+\mathrm{Mn}_{\mathrm{Mg}}^{\times} \rightarrow \mathrm{V}_{\mathrm{O}}^{\bullet}+\mathrm{Mn}_{\mathrm{Mg}}^{\bullet}+2 \mathrm{e}^{-} .
$$

We investigated the spin-configuration explicitly by controlling the system multiplicity, with the possible spin being (a) an IS quartet or (b and c) a HS sextuplet. From the energies presented in Table 4, it is clear that $E_{\mathrm{f}}\left(\mathrm{F}^{2+}\right)$ is preferred in HS, with $E_{\mathrm{f}}\left(\mathrm{F}^{2+}\right)=10.48$ and $10.41 \mathrm{eV}$ for $\mathrm{Mn}_{\text {surf }}$ and $\mathrm{Mn}_{\text {sub }}$, respectively. However, as (b) and (c) are indistinguishable by spin-state alone, comparison of the Mulliken spin populations is necessary, which shows that the spin-density on the Mn dopant is $\sim 4.7 \mathrm{e}$ and $\sim 4.6$ e for $\mathrm{Mn}_{\text {surf }}$ and $\mathrm{Mn}_{\text {sub }}$, respectively. Thus, we can

Table $4 E_{\mathrm{f}}\left(\mathrm{F}^{q+}\right)$ for the $\mathrm{Mn}-\mathrm{MgO}(100)$ surface, as calculated with $\varepsilon_{\mathrm{f}}$ set at the vacuum (VBM) level. Both intermediate-spin (IS) and high-spin (HS) configurations were considered for $q=1$ and 2; see the text for detailed justification. $E_{f}\left(F^{q+}\right)$ for a low-spin $\mathrm{MgO}(100)$ surface are also presented from

\begin{tabular}{|c|c|c|c|c|c|c|}
\hline$q$ & Spin & \multicolumn{2}{|l|}{$\mathrm{Mn}_{\text {surf }}$} & \multicolumn{2}{|l|}{$\mathrm{Mn}_{\text {sub }}$} & $\frac{\mathrm{MgO}^{42}}{\mathrm{~B} 3 \mathrm{LYP}}$ \\
\hline 0 & IS & $6.16(6.16)$ & $5.86(5.86)$ & $6.13(6.13)$ & $5.85(5.85)$ & $6.59(6.59)$ \\
\hline 1 & HS & $7.92(1.77)$ & $7.75(1.36)$ & $7.88(1.73)$ & $7.71(1.32)$ & - \\
\hline 2 & IS & $11.65(-0.65)$ & $12.24(-0.54)$ & $11.09(-1.21)$ & $11.11(-1.67)$ & $10.87(-2.05)$ \\
\hline 2 & HS & $10.48(-1.82)$ & $10.38(-2.40)$ & $10.41(-1.89)$ & $10.28(-2.50)$ & - \\
\hline
\end{tabular}
literature, with values updated using the B3LYP XC functionals, equivalent basis sets and a VBM of $-6.46 \mathrm{eV} .{ }^{42} \mathrm{All}$ values are in eV 


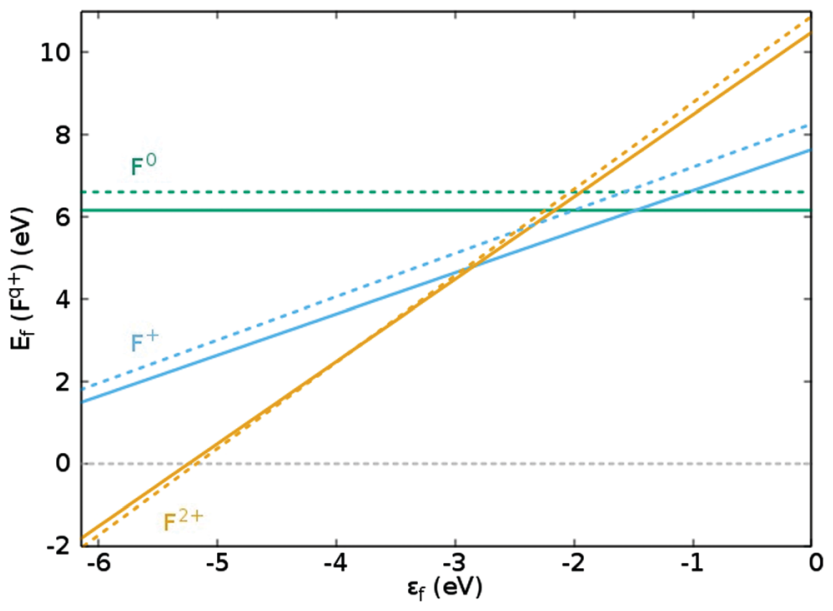

Fig. $4 E_{f}$ for $\mathrm{F}^{q+}$-centres using the B3LYP XC functional, with solid lines representing $\mathrm{Mn}_{\text {surf }}-\mathrm{MgO}$, with $\varepsilon_{\mathrm{f}}$ ranging from the VBM $(-6.15 \mathrm{eV})$ through to vacuum level $(0 \mathrm{eV})$, and dashed lines representing the same defects on a pristine MgO surface, as calculated in Table 4 from the work of Downing et al. ${ }^{42}$ Dashed green, blue and yellow lines show $E_{\mathrm{f}}$ when the defect charge is $q=0,1$ and 2 , respectively (i.e. $\mathrm{F}^{0}, \mathrm{~F}^{+}$and $\mathrm{F}^{2+}$ ).

conclude that both electrons are removed from the vacancy, i.e. $\mathrm{V}_{\mathrm{O}}^{\times} \rightarrow \mathrm{V}_{\mathrm{O}}^{\bullet}+2 \mathrm{e}^{-}$, irrespective of Mn position or XC functional. We again note that $E_{\mathrm{f}}\left(\mathrm{F}^{2+}\right)$ for $\mathrm{Mn}-\mathrm{MgO}$ is generally lower than for $\mathrm{MgO}$, in the favoured HS state, though not when $\varepsilon_{\mathrm{f}}$ drops towards the VBM. Perhaps more pertinently, $E_{\mathrm{f}}\left(\mathrm{F}^{+}\right)>E_{\mathrm{f}}\left(\mathrm{F}^{2+}\right)$ for $\mathrm{Mn}_{\text {surf }}$ when $\varepsilon_{\mathrm{f}}$ is lower than $-2.84(-2.89) \mathrm{eV}$, and $\mathrm{F}^{2+}$-centre formation is exothermic when $\varepsilon_{\mathrm{f}}$ is lower than $-5.21(-5.14) \mathrm{eV}$, i.e. p-type, when using the B3LYP(B97-3) XC functional (Fig. 4).

As illustrated in Fig. 5, the IS VIP for the $\mathrm{F}^{0}$-centre with an $\mathrm{Mn}_{\text {surf }}$ dopant is found to be $2.62 \mathrm{eV}$ whereas the HS VIP is $2.94 \mathrm{eV}$. Referring to our prior comment that HS corresponds to parallel alignment of the vacancy electrons and the $\mathrm{Mn} 3 \mathrm{~d}$ states, we can re-affirm the larger $E_{\mathrm{f}}\left(\mathrm{F}^{+}\right)$for a HS configuration is based

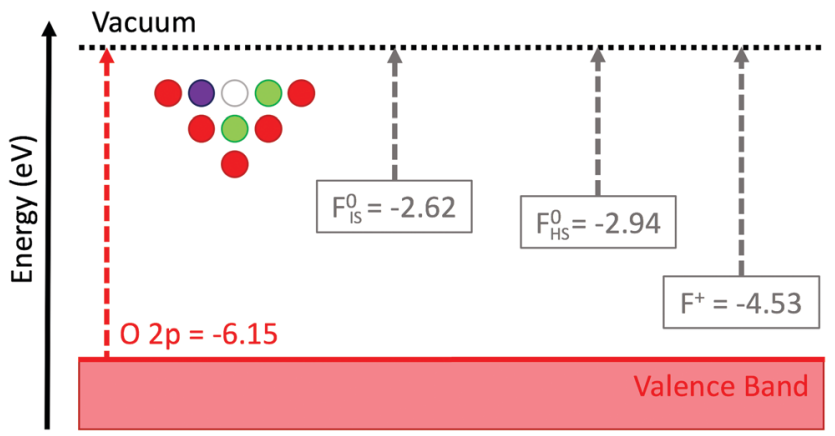

Fig. 5 Intrinsic defect levels, relative to vacuum, for F-centres on the $\mathrm{Mn}_{\text {surf }}-\mathrm{MgO}(100)$ surface. The colour scheme of the atoms is the same as Fig. 3, with an additional white circle to show an surface oxygen vacancy. The colour scheme of the electronic transitions matches the origin of electrons: the valence band is $\mathrm{O} 2 \mathrm{p}$ states, with the $\mathrm{F}^{0}$ and $\mathrm{F}^{+}$defect states positioned in the band gap. $\mathrm{F}_{\mathrm{HS}}^{O}$ and $\mathrm{F}_{\mathrm{IS}}^{O}$ are used to denote parallel and antiparallel alignment, respectively, of the oxygen vacancy electrons with the $\mathrm{Mn} 3 \mathrm{~d}$ states. The energies presented are calculated with the B3LYP XC functional, and the adiabatic ionisation potential (AIP) was calculated as $1.48,1.76$ and $2.84 \mathrm{eV}$ for the $\mathrm{F}_{\mathrm{IS}}^{\mathrm{O}} \mathrm{F}_{\mathrm{HS}}^{\mathrm{O}}$ and $\mathrm{F}^{+}$defect states, respectively. on the greater stability of the highest occupied molecular orbital (HOMO) when compared to an anti-parallel (IS) configuration. The VIP of the oxygen vacancy is similar for $\mathrm{Mn}_{\text {sub: }}: 2.51$ and $2.92 \mathrm{eV}$ for the IS and HS configuration, respectively. The upwards shift of the HOMO for an anti-parallel alignment, which is between 0.3 and $0.4 \mathrm{eV}$, gives a reasonable approximation to the exchange coupling energy, whereas the position of the parallel aligned $\mathrm{V}_{\mathrm{O}}$ state at $\sim-2.9 \mathrm{eV}$ is only slightly lower than the $-3.05 \mathrm{eV}$ calculated previously for an $\mathrm{F}^{0}$-centre on an $\mathrm{MgO}(100)$ surface. ${ }^{42}$ The increased stability of the parallel states is in agreement with previous observations for ferromagnetic $\mathrm{Mn}-\mathrm{O}$ and $\mathrm{Mn}-\mathrm{C}$ coupling in doped $\mathrm{MgO},{ }^{25}$ though higher concentrations of $\mathrm{Mn}$ dopants would result in strong Mn-Mn anti-parallel coupling. ${ }^{26,30}$

Using the lower energy IS $\mathrm{F}^{+}$-centre as our starting point, we also calculated the energy required to remove a second electron from the $\mathrm{V}_{\mathrm{O}}$ site to form a HS $\mathrm{F}^{2+}$-centre. The VIP is $4.53 \mathrm{eV}$ for $\mathrm{Mn}_{\text {surf }}$ with a very similar result of $4.52 \mathrm{eV}$ for $\mathrm{Mn}_{\text {sub }}$, very close to the previously calculated 2nd VIP of an $\mathrm{MgO}$ F-centre $(4.55 \mathrm{eV})$. Coupled with Mulliken analysis, we conclude that the second electron is also ionised from the oxygen vacancy, which means that the highest $\mathrm{Mn} 3 \mathrm{~d}$ states must be below $-4.5 \mathrm{eV}$, implying that they are stabilised by the presence of the $\mathrm{V}_{\mathrm{O}}$ when compared to the pristine surface, for which the VIP was 4.2 to $4.4 \mathrm{eV}$ (Section 4.1).

\section{$5 \mathrm{CO}_{2}$ adsorption on $\mathrm{Mn}$-doped $\mathrm{MgO}(100)$ surface}

Within the reaction process of $\mathrm{CO}_{2}$ to $\mathrm{CH}_{3} \mathrm{OH}$ conversion, $\mathrm{CO}_{2}$ is bound to a surface oxygen vacancy and undergoes hydrogenation, leading to the formation of $\mathrm{CH}_{3} \mathrm{OH}$ and the removal of the surface defect; $\mathrm{CO}$ is then used to regenerate the defect sites via its transformation to $\mathrm{CO}_{2}$, completing the catalytic cycle. ${ }^{73}$ Such a reaction cycle is transferable and highly tunable via modification of the surface as we have recently shown for F-centres on $\mathrm{MgO}^{42,43}$ As a fundamental step in this topically relevant reaction, a number of $\mathrm{CO}_{2}$ adsorption processes were considered here for the $\mathrm{Mn}-\mathrm{MgO}(100)$ surfaces investigated in Section 4. The $\mathrm{CO}_{2}$ adsorbate was aligned with the $\mathrm{O}-\mathrm{C}-\mathrm{O}$ axis along either the Cartesian $x$ - or $z$-axes of the system, "parallel" or "perpendicular" to the surface. ${ }^{42} \mathrm{~A}$ third $\mathrm{CO}_{2}$ adsorbate orientation was included for $\mathrm{Mn}_{\text {surf }}$, with the $\mathrm{O}-\mathrm{C}-\mathrm{O}$ axis aligned along the $y$-axis of the model. The adsorption energy, $E_{\text {ads }}$, for the $\mathrm{CO}_{2}$ molecule was defined as:

$$
E_{\text {ads }}\left(\mathrm{CO}_{2}\right)=E\left(\mathrm{CO}_{2}-\mathrm{MnMgO}\right)-E\left(\mathrm{CO}_{2}\right)-E(\mathrm{MnMgO}),
$$

where $E\left(\mathrm{CO}_{2}\right)$ and $E\left(\mathrm{CO}_{2}-\mathrm{MnMgO}\right)$ are the energies of the gas phase $\mathrm{CO}_{2}$ and $\mathrm{Mn}-\mathrm{MgO}$ adsorbed $\mathrm{CO}_{2}$ systems, respectively. Energetic errors from basis set superposition were not explicitly calculated; however we expect them to be similar to the quantity calculated previously for $\mathrm{CO}_{2}$ chemisorbed on $\mathrm{MgO}$ $(0.15-0.18 \mathrm{eV}) .^{42}$ An HS configuration was considered for the $\mathrm{O}_{5 \mathrm{c}}$ site and $\mathrm{F}^{2+}$ defects, with the $\mathrm{F}^{0}$ defects modelled using the lower-energy IS configuration, and both IS and HS configurations 
investigated for $\mathrm{F}^{+}$-centres. We note that the $\mathrm{CO}_{2}$ molecule has a closed-shell (singlet) electronic configuration in the gas-phase and so electron transfer to an adsorbed $\mathrm{CO}_{2}$ could be to either the $\alpha$ - or $\beta$-channels with equal probability. At this stage, we have limited our investigation to the determination of adsorbed structures and analysis of any electron transfer, with adsorption profiles and barriers reserved for future work.

\section{$5.1 O_{5 c}$ site}

The structures for chemisorbed $\mathrm{CO}_{2}$ parallel to the $\mathrm{Mn}_{\text {surf }}$ $\mathrm{MgO}(100)$ surface are shown in Fig. 6(a) and (b), whilst $\mathrm{CO}_{2}$ chemisorption parallel to the $\mathrm{Mn}_{\text {sub }}-\mathrm{MgO}$ surface is shown in Fig. 6(c). The $\mathrm{CO}_{2}$ physisorbed perpendicular to the $\mathrm{O}_{5 c}$ site is not shown as significant interactions were not seen, which was expected,

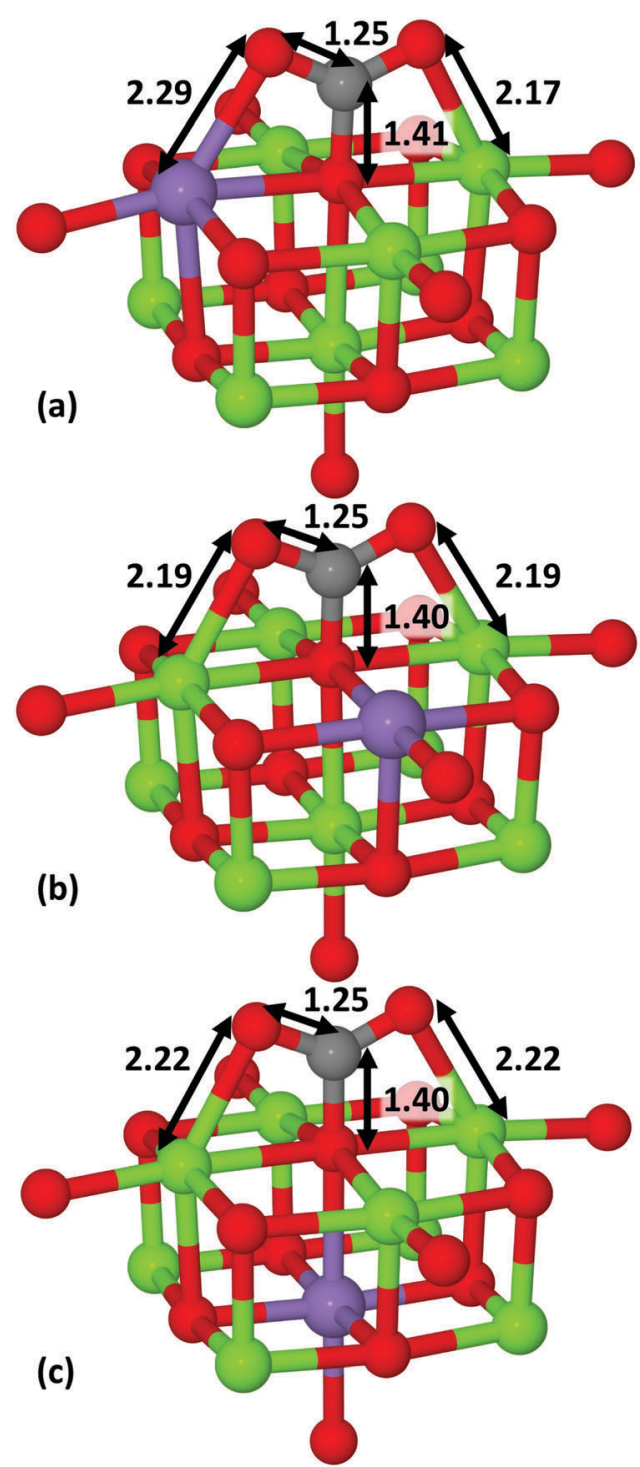

Fig. $6 \mathrm{CO}_{2}$ adsorbed on the $\mathrm{Mn}-\mathrm{MgO}(100)$ surface, where the $\mathrm{CO}_{2}$ molecule is adsorbed in the $x y$-surface plane. In (a) and (b), the $\mathrm{CO}_{2}$ molecule is positioned in the $x$ - and $y$-axes, respectively, over an $M_{\text {surf }}-M g O$ substrate; in (c), the $\mathrm{CO}_{2}$ molecule is adsorbed over an $\mathrm{Mn}_{\text {sub }}-\mathrm{MgO}$ substrate. $\mathrm{O}$ atoms are shown in red, $\mathrm{Mg}$ in green, $\mathrm{Mn}$ in purple and $\mathrm{C}$ in grey. Bond lengths are given in $\AA$. based on previous results for $\mathrm{MgO},{ }^{42}$ and the data presented in the ESI $\uparrow$ shows that the interaction is negligible. In experiment, van der Waals interactions that are absent from our calculations would, perhaps, allow the $\mathrm{CO}_{2}$ to be physisorbed near the Mn-MgO surface.

For the $x$ - and $y$-axis aligned adsorbates, a carbonate species forms, and $E_{\text {ads }}\left(\mathrm{CO}_{2}\right)$ on the $\mathrm{O}_{5 c}$ site ranges between -0.66 and $-0.86 \mathrm{eV}$, which is similar to that observed for $\mathrm{MgO} ;{ }^{42}$ full results are included in the ESI. $\dagger$ We note for $\mathrm{Mn}_{\text {surf }}$ that stronger $\mathrm{CO}_{2}$ adsorption is seen for $y$-axis alignment, compared to $x$-axis, which can be correlated with the longer $\mathrm{Mn}-\mathrm{O}$ bond of $2.29 \AA$ between the (100) surface and the $\mathrm{CO}_{2}$ in the latter system. Mulliken analysis shows that there is partial withdrawal of 0.5 e from the $\mathrm{O}_{5 \mathrm{c}}$ and neighbouring $\mathrm{Mg}$ atoms to the adsorbate; however the Mn-dopant retains its $\mathrm{d}^{5}$ configuration, which hinders charge transfer.

Comparison of the different XC functionals shows consistently stronger binding when using B97-3, with the interactions around $10 \%$ stronger than for B3LYP. This result is consistent with the parameterisation of this XC functional towards thermochemical processes such as chemisorption, supporting stronger electron localisation.

\section{$5.2 \quad \mathbf{F}^{0}$-centre}

For a neutral oxygen vacancy, the $z$-axis (vertically) aligned $\mathrm{CO}_{2}$ dissociates to produce a defect-free surface and a CO molecule, as shown in Fig. 7(a). Table 5 shows that this process is strongly exothermic $(\sim-3 \mathrm{eV})$ due to the healing of the oxygen vacancy. Strong adsorption also occurs when $\mathrm{CO}_{2}$ is aligned parallel to the surface, with $E_{\text {ads }}\left(\mathrm{CO}_{2}\right) \approx-2 \mathrm{eV}$. The strong binding results in a bent $\mathrm{CO}_{2}$ geometry, as seen previously for $\mathrm{F}^{0}$-centre on $\mathrm{MgO} ;{ }^{42}$ however healing of the oxygen vacancy does not occur in this particular case. Regardless of the position of the Mn dopant, the $\mathrm{CO}_{2}$ rotates so that the central $\mathrm{C}$ atom is directed towards a surface $\mathrm{Mg}$, rather than downwards into the vacancy as seen for undoped $\mathrm{MgO} .{ }^{42}$ It is noted that, in the $y$-axis orientation on $\mathrm{Mn}_{\text {surf }}-\mathrm{MgO}$, the $\mathrm{CO}_{2}$ is able to rotate towards either an $\mathrm{Mn}$ or $\mathrm{Mg}$ atom, however, the latter is favoured.

\section{$5.3 \quad \mathbf{F}^{+}$-centre}

Due to the energetic competition between the IS and HS $\mathrm{F}^{+}$-centres, both were considered as adsorption sites for $\mathrm{CO}_{2}$ (Table 6), which resulted in a range of adsorption strengths. $E_{\text {ads }}\left(\mathrm{CO}_{2}\right)$ is greatest for IS $\mathrm{Mn}_{\text {surf }}-\mathrm{MgO}$ with the adsorbate aligned along the $x$-axis of the surface $(-2.00 \mathrm{eV})$. Fig. 8(a) shows that the $\mathrm{CO}_{2}$ has dissociated, with one $\mathrm{O}$ healing the surface vacancy and the remaining CO coordinated to a surface $\mathrm{Mg}$. Mulliken analysis shows that the electron previously trapped at the $\mathrm{F}^{+}$-centre has reduced the $\mathrm{Mn}^{2+}$ cation to $\mathrm{Mn}^{+}$, which has a spin-density of $3.90 \mathrm{e}$; further calculations would be necessary to determine if an entirely LS configuration is preferable for the $\mathrm{Mn}$ cation. For the same system with a HS configuration, no dissociation is observed and instead the vacancy-trapped electron transfers to the $\mathrm{CO}_{2}$, hence the smaller $E_{\mathrm{ads}}\left(\mathrm{CO}_{2}\right)$. The second greatest $E_{\text {ads }}\left(\mathrm{CO}_{2}\right)$ is with the $\mathrm{CO}_{2}$ aligned in the $y$-axis of an IS-configured surface $(-1.38 \mathrm{eV})$ : the $\mathrm{CO}_{2}$ remains parallel to 


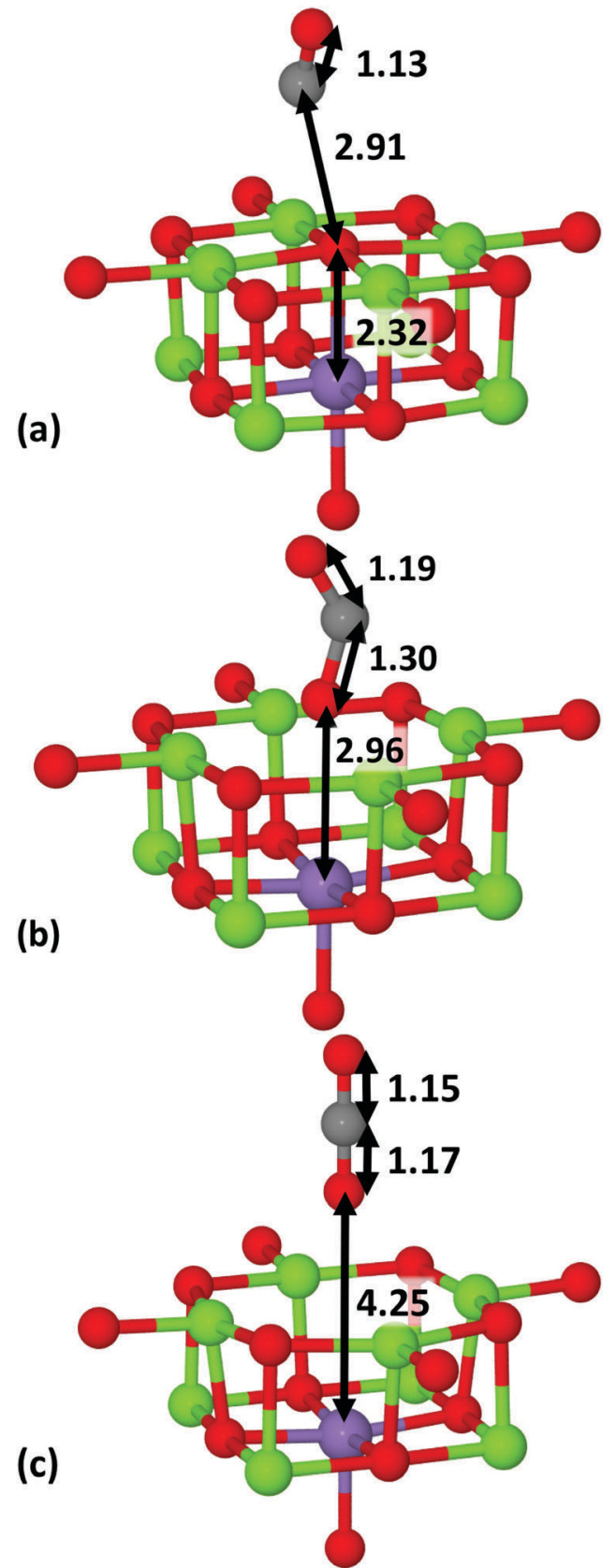

Fig. $7 \mathrm{CO}_{2}$ adsorbed on the $\mathrm{Mn}_{\text {sub }}-\mathrm{MgO}(100)$ surface at an (a) $\mathrm{F}^{\circ}$-centre, (b) $\mathrm{F}^{+}$-centre and (c) $\mathrm{F}^{2+}$-centre. $\mathrm{O}$ atoms are shown in red, $\mathrm{Mg}$ in green, $\mathrm{Mn}$ in purple and $\mathrm{C}$ in grey. Bond lengths are given in $\AA$.

Table $5 E_{\text {ads }}\left(\mathrm{CO}_{2}\right)$ on $\mathrm{F}^{0}$-centres at the (100) surface. Also presented are previously calculated results for $\mathrm{CO}_{2}$ adsorption on $\mathrm{MgO}$ using the B3LYP $\mathrm{XC}$ functional and similar basis sets. ${ }^{42}$ All values are given in $\mathrm{eV}$

\begin{tabular}{llll}
\hline & $\mathrm{CO}_{2}$ axis & B3LYP & B97-3 \\
\hline $\mathrm{Mn}_{\text {surf }}$ & $x$ & -2.00 & -1.74 \\
& $y$ & -2.25 & -1.98 \\
& $z$ & -3.13 & -2.80 \\
$\mathrm{Mn}_{\text {sub }}$ & $x$ & -2.24 & -1.98 \\
& $z$ & -3.20 & -2.87 \\
$\mathrm{Mg}^{42}$ & $x$ & -2.36 & - \\
& $z$ & -3.52 & -
\end{tabular}

Table $6 E_{\text {ads }}\left(\mathrm{CO}_{2}\right)$ on $\mathrm{F}^{+}$-centre sites, with an IS (HS) electronic configuration, on $\mathrm{Mn}-\mathrm{MgO}(100)$ surface. Also presented are previously calculated results for $\mathrm{CO}_{2}$ adsorption on $\mathrm{MgO}$ using the B3LYP XC functional and similar basis sets. ${ }^{42}$ All values are given in $\mathrm{eV}$

\begin{tabular}{llll}
\hline & $\mathrm{CO}_{2}$ axis & B3LYP & B97-3 \\
\hline $\mathrm{Mn}_{\text {surf }}$ & $x$ & $-2.00(-0.62)$ & $-1.64(-0.48)$ \\
& $y$ & $-1.38(-0.80)$ & $-1.06(-0.64)$ \\
& $z$ & $-0.90(-1.12)$ & $-0.76(-0.97)$ \\
$\mathrm{Mn}_{\text {sub }}$ & $x$ & $-0.64(-0.85)$ & $-0.49(-0.69)$ \\
& $z$ & $-0.99(-1.18)$ & $-0.85(-1.05)$ \\
$\mathrm{Mg}^{42}$ & $x$ & -0.71 & - \\
& $z$ & -1.11 & -
\end{tabular}

(a)
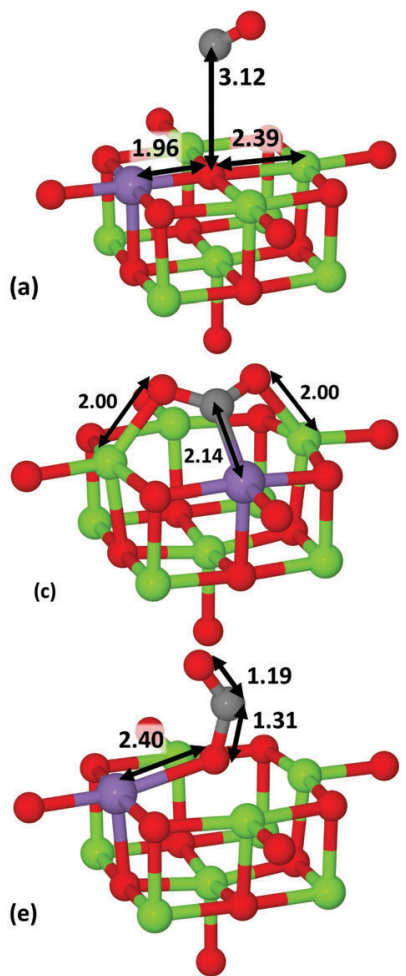

(b)

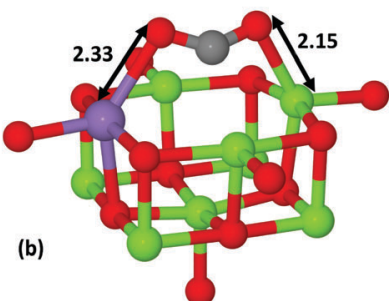

(d)
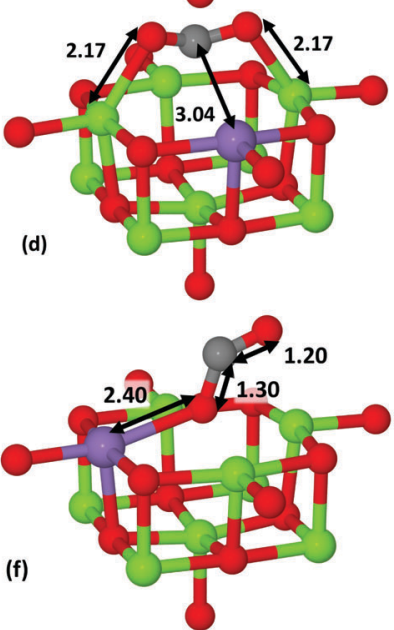

Fig. $8 \mathrm{CO}_{2}$ adsorbed on the $\mathrm{Mn}_{\text {surf }}-\mathrm{MgO}(100)$ surface at an $\mathrm{F}^{+}$-centre with the adsorbate aligned ( $a$ and $b$ ) in the $x$-axis, ( $c$ and $d)$ in the $y$-axis, and (e and f) in the $z$-axis. (a, c and e) Are with anti-parallel spin for the vacancy and the $\mathrm{Mn} 3 \mathrm{~d}$ states, i.e. IS configuration, and (b), (d) and (f) are parallel spin for the vacancy and the $\mathrm{Mn} 3 \mathrm{~d}$ states, i.e. HS configuration. $\mathrm{O}$ atoms are shown in red, $\mathrm{Mg}$ in green, $\mathrm{Mn}$ in purple and $\mathrm{C}$ in grey. Bond lengths are given in $\AA$.

the surface but the $\mathrm{C}$ bonds directly to the $\mathrm{Mn}$, with the two atoms separated by $2.14 \AA$ compared to $2.61 \AA$ for the HS equivalent as shown in Fig. 8(c) and (d), respectively. The spindensity is $4.08 \mathrm{e}$ in the former case, which is $\sim 0.76$ e lower than for HS (4.76 e) and again indicates that the vacancy electron has moved to the $\mathrm{Mn}$.

In contrast to the above, $E_{\text {ads }}\left(\mathrm{CO}_{2}\right)$ for $z$-axis aligned $\mathrm{CO}_{2}$ on the $\mathrm{Mn}_{\text {surf }}$ is stronger for HS than IS, with no chemisorption, which indicates that exchange coupling benefits physisorption. The resulting bent $\mathrm{CO}_{2}$ remains perpendicular to the surface 
Table $7 E_{\text {ads }}\left(\mathrm{CO}_{2}\right)$ on $\mathrm{F}^{2+}$-centres. Also presented are previously calculated results for $\mathrm{CO}_{2}$ adsorption on $\mathrm{MgO}$ using the B3LYP XC functional and similar basis sets. ${ }^{42}$ All values are given in $\mathrm{eV}$

\begin{tabular}{llrr}
\hline & $\mathrm{CO}_{2}$ axis & B3LYP & B97-3 \\
\hline $\mathrm{Mn}_{\text {surf }}$ & $x$ & 0.90 & 1.14 \\
& $y$ & 0.50 & 0.00 \\
& $z$ & -0.09 & -0.11 \\
$\mathrm{Mn}_{\text {sub }}$ & $x$ & 0.24 & 0.52 \\
& $z$ & -0.12 & -0.13 \\
$\mathrm{Mg}^{42}$ & $x$ & 0.11 & - \\
& $z$ & 0.04 & - \\
& & & \\
& & & \\
\hline
\end{tabular}

for both systems [Fig. 8(e) and (f)], with the terminal O only $\sim 0.7 \AA$ above the surface plane, but the difference in $E_{\text {ads }}\left(\mathrm{CO}_{2}\right)$ between HS and IS is $0.22 \mathrm{eV}$. Similar differences are seen for the $\mathrm{Mn}_{\text {sub }}$ systems [Fig. $\left.7(\mathrm{~b})\right]$, where $E_{\text {ads }}\left(\mathrm{CO}_{2}\right)$ for HS is consistently $\sim 0.2 \mathrm{eV}$ greater than for IS. Mulliken analysis of the $\mathrm{CO}_{2}$ when $x$-axis aligned on $\mathrm{Mn}_{\text {sub }}-\mathrm{MgO}$ shows that the spindensity is 0.69 and $0.84 \mathrm{e}$ when using IS and HS configurations, respectively, which correlates charge transfer with adsorption energy; we also note that the majority of this spin density is located on the central $\mathrm{C}$ atom.

\section{$5.4 \quad \mathbf{F}^{2+}$-centre}

$E_{\text {ads }}\left(\mathrm{CO}_{2}\right)$ on $\mathrm{HS} \mathrm{F}^{2+}$-centres is presented in Table 7, with similar structures observed for $\mathrm{CO}_{2}$ adsorbed on $\mathrm{Mn}_{\text {sub }}-$ and $\mathrm{Mn}_{\text {surf }}$ MgO [Fig. 7(c)]. Bonding is marginally exothermic for $z$-axis aligned $\mathrm{CO}_{2}$, with the lack of bend in the adsorbate suggesting that no significant charge transfer occurs, which is consistent with results for undoped $\mathrm{MgO}^{42}$ and confirmed by Mulliken analysis. $\mathrm{CO}_{2}$ adsorption is endothermic when the molecule is aligned with the $x$ - or $y$-axis; as separation of the $\mathrm{CO}_{2}$ and surface would be more favourable, this is a local minimum. Electron density transfers from the $\mathrm{Mn}$ atom to the $\mathrm{CO}_{2}$ to form a $\mathrm{CO}_{2}{ }^{-} / \mathrm{Mn}^{3+}$ surface complex, with greater charge transfer when the $\mathrm{Mn}$ interacts with a terminal $\mathrm{O}(x$-axis) rather than the $\mathrm{C}$ atom $(y$-axis), which correlates with the more endothermic nature of the $x$-axis aligned adsorption $(0.90 \mathrm{eV}$ compared to $0.50 \mathrm{eV})$.

\section{Summary and conclusions}

We have performed embedded-cluster QM/MM calculations for Mn-doped MgO, studying bulk and (100) surface systems, as well as testing the reactivity of the doped material using $\mathrm{CO}_{2}$ adsorption as a representative catalytic process. Low concentration Mn-doping is endothermic for isovalent bulk defects, irrespective of a low or high $p\left(\mathrm{O}_{2}\right)$ reference environment, with the Mn 3d levels positioned in the band gap $\sim 4.2 \mathrm{eV}$ below the vacuum level, however, Mn-doping is energetically favourable in higher oxidation states, especially under p-type conditions. The formation of isovalent Mn-doped (100) MgO surfaces is marginally exothermic at high $p\left(\mathrm{O}_{2}\right)$, with subsurface doping being exothermic; however higher oxidation states become more favourable in p-type conditions.

Once present, an isovalent Mn-dopant aids the formation of oxygen vacancies, i.e. $\mathrm{F}$-centres, on the (100) surface: $\mathrm{F}^{+}$-centres particularly benefit from an exchange-coupling mechanism between the trapped electrons and the Mn 3d-states, with a parallel aligned electron $0.32 \mathrm{eV}$ lower in energy than an antiparallel aligned electron when using the B3LYP XC functional. In general, formation energies for $\mathrm{F}^{0}$ and $\mathrm{F}^{2+}$-centres indicate their prevalence in $\mathrm{n}$ - and p-type environments, respectively, in broad agreement with findings for undoped MgO; in future work we will extend this analysis to Mn-dopants in higher oxidation states.

When a $\mathrm{CO}_{2}$ probe molecule is adsorbed on the pristine and defective $\mathrm{Mn}-\mathrm{MgO}(100)$ surface, the interaction between substrate and adsorbate is dependent on both defect charge and adsorbate orientation. Strongest adsorption is for $\mathrm{CO}_{2}$ over an $\mathrm{F}^{0}$-centre, with the $\mathrm{CO}_{2}$ dissociating when aligned perpendicular to the surface so that the oxygen vacancy can be filled by one of the oxygen atoms from the $\mathrm{CO}_{2}$ molecule. We also observe strong binding between $\mathrm{F}^{+}$-centres and $\mathrm{CO}_{2}$ when the Mn-dopant is positioned at the surface, with interaction strengths less varied when the $\mathrm{Mn}$ is subsurface. In general, positioning of an Mn-dopant subsurface implicitly affects $\mathrm{CO}_{2}$ adsorption through exchange coupling effects, whereas Mn dopants on the surface strongly influence the chemical reactivity, with distinctly different interactions compared to MgO. In general our results justify further investigation of the doping of stable alkaline-earth metal oxides with transition metal species, which we will continue in our future work with an emphasis on catalytic reactivity: it has been previously noted that high-valence dopants activate molecular adsorbates for other transition metal dopants in rocksalt oxides ${ }^{78}$ and clearly we need to investigate this further for Mn-MgO.

\section{Acknowledgements}

The authors are grateful to David Scanlon and John Buckeridge for discussions associated with this work. AJL acknowledges the Ramsay Memorial Trust and University College London for the provision of a Ramsay Fellowship. CAD acknowledges the Molecular Modelling and Materials Science Industrial Doctorate Centre (M3S IDC) and the Science and Technology Facilities Council (STFC) for funding. AJL, TWK, PS, AAS and CRAC acknowledge funding from EPSRC grants EP/IO30662/1 and EP/K038419/1. The authors acknowledge the use of the ARCHER high-performance computing facilities, and associated support services, via our membership of the UK HPC Materials Chemistry Consortium (EP/L000202).

\section{References}

1 S. Wang, S. Yan, X. Ma and J. Gong, Energy Environ. Sci., 2011, 4, 3805-3819.

2 S. Choi, J. H. Drese and C. W. Jones, ChemSusChem, 2009, 2, 796-854.

3 H. A. Al-Abadleh and V. H. Grassian, Surf. Sci. Rep., 2003, 52, 63-161.

4 D. P. Woodruff, Chem. Rev., 2013, 113, 3863-3886.

5 C. Noguera, Physics and Chemistry at Oxide Surfaces, Cambridge University Press, 1996. 
6 A. J. Logsdail, D. O. Scanlon, C. R. A. Catlow and A. A. Sokol, Phys. Rev. B: Condens. Matter Mater. Phys., 2014, 90, 155106.

7 A. J. Logsdail, D. Mora-Fonz, D. O. Scanlon, C. R. A. Catlow and A. A. Sokol, Surf. Sci., 2015, 642, 58-65.

8 G. Pacchioni, ChemPhysChem, 2003, 4, 1041-1047.

9 K. Honkala, Surf. Sci. Rep., 2014, 69, 366-388.

10 H. Hattori, Appl. Catal., A, 2001, 222, 247-259.

11 J. Goniakowski and C. Noguera, Surf. Sci., 1995, 340, 191-204.

12 G. Pacchioni and H. Freund, Chem. Rev., 2013, 113, 4035-4072.

13 D. K. Kanan and E. A. Carter, J. Phys. Chem. C, 2012, 116, 9876-9887.

14 R. Hammami, A. Dhouib, S. Fernandez and C. Minot, Catal. Today, 2008, 139, 227-233.

15 N. Nilius and H.-J. Freund, Acc. Chem. Res., 2015, 48, 1532-1539.

16 E. W. McFarland and H. Metiu, Chem. Rev., 2013, 113, 4391-4427.

17 N. Nilius, J. Phys.: Condens. Matter, 2015, 27, 303001.

18 A. Cimino and V. Indovina, J. Catal., 1974, 33, 493-496.

19 P. Koidl and K. W. Blazey, J. Phys. C: Solid State Phys., 1976, 9, L167.

20 R. Mariscal, J. Soria, M. Pena and J. Fierro, J. Catal., 1994, 147, 535-543.

21 M. Abramishvili, Z. Akhvlediani, M. Galustashvili, G. Dekanozishvili, T. Kalabegishvili, V. Kvatchadze and V. Tavkhelidze, J. Mod. Phys., 2011, 2, 6759.

22 M. Königstein, F. Cora and C. R. A. Catlow, J. Solid State Chem., 1998, 137, 261-275.

23 H. Gripenberg, S. Seetharaman and L. Staffansson, Chem. Scr., 1979, 13, 162-164.

24 K. D. Heath, W. C. Mackrodt, V. R. Saunders and M. Causà, J. Mater. Chem., 1994, 4, 825-829.

25 V. Sharma, G. Pilania and J. E. Lowther, AIP Adv., 2011, 1, 032129.

26 L.-J. Shi, Phys. Lett. A, 2010, 374, 1292-1296.

27 S. Azzaza, M. El-Hilo, S. Narayanan, J. J. Vijaya, N. Mamouni, A. Benyoussef, A. El Kenz and M. Bououdina, Mater. Chem. Phys., 2014, 143, 1500-1507.

28 S. Meskine, A. Boukortt, R. Hayn and A. Zaoui, Phys. Status Solidi B, 2014, 251, 845-849.

29 P. Wu, G. Cao, F. Tang and M. Huang, Comput. Mater. Sci., 2014, 86, 180-185.

30 P. Panigrahi, T. Hussain, C. M. Araujo and R. Ahuja, J. Phys.: Condens. Matter, 2014, 26, 265801.

31 P. Panigrahi, C. M. Araujo, T. Hussen and R. Ahuja, Sci. Technol. Adv. Mater., 2014, 15, 035008.

32 N. A. Richter, S. Sicolo, S. V. Levchenko, J. Sauer and M. Scheffler, Phys. Rev. Lett., 2013, 111, 045502.

33 F. Kröger and H. Vink, Solid State Phys., 1956, 3, 307-435.

34 E. Scorza, U. Birkenheuer and C. Pisani, J. Chem. Phys., 1997, 107, 9645-9658.

35 P. V. Sushko, A. L. Shluger and C. R. A. Catlow, Surf. Sci., 2000, 450, 153-170.

36 P. Sushko, J. Gavartin and A. Shluger, J. Phys. Chem. B, 2002, 106, 2269-2276.
37 Y. Wang, H. N. Nguyen and T. N. Truong, Chem. - Eur. J., 2006, 12, 5859-5867.

38 E. Florez, P. Fuentealba and F. Mondragon, Catal. Today, 2008, 133, 216-222.

39 C. Qin, Chem. Phys. Lett., 2008, 460, 457-460.

40 G. Pacchioni and H.-J. Freund, Chem. Rev., 2013, 113, 4035-4072.

41 K. Kwapien, J. Paier, J. Sauer, M. Geske, U. Zavyalova, R. Horn, P. Schwach, A. Trunschke and R. Schlögl, Angew. Chem., Int. Ed., 2014, 53, 8774-8778.

42 C. A. Downing, A. A. Sokol and C. R. A. Catlow, Phys. Chem. Chem. Phys., 2014, 16, 184-195.

43 C. A. Downing, A. A. Sokol and C. R. A. Catlow, Phys. Chem. Chem. Phys., 2014, 16, 21153-21156.

44 S. Metz, J. Kästner, A. A. Sokol, T. W. Keal and P. Sherwood, Wiley Interdiscip. Rev.: Comput. Mol. Sci., 2014, 4, 101-110.

45 J. Kaestner, J. M. Carr, T. W. Keal, W. Thiel, A. Wander and P. Sherwood, J. Phys. Chem. A, 2009, 113, 11856-11865.

46 P. Sherwood, A. H. de Vries, M. F. Guest, G. Schreckenbach, C. R. A. Catlow, S. A. French, A. A. Sokol, S. T. Bromley, W. Thiel, A. J. Turner, S. Billeter, F. Terstegen, S. Thiel, J. Kendrick, S. C. Rogers, J. Casci, M. Watson, F. King, E. Karlsen, M. Sjovoll, A. Fahmi, A. Schafer and C. Lennartz, J. Mol. Struct.: THEOCHEM, 2003, 632, 1-28.

47 M. Valiev, E. J. Bylaska, N. Govind, K. Kowalski, T. P. Straatsma, H. J. J. V. Dam, D. Wang, J. Nieplocha, E. Apra, T. L. Windus and W. A. de Jong, Comput. Phys. Commun., 2010, 181, 1477-1489.

48 J. D. Gale, J. Chem. Soc., Faraday Trans., 1997, 93, 629-637. 49 J. D. Gale and A. L. Rohl, Mol. Simul., 2003, 29, 291-341.

50 J. Gale, Z. Kristall., 2005, 220, 552-554.

51 A. D. Becke, J. Chem. Phys., 1993, 98, 5648-5652.

52 C. T. Lee, W. T. Yang and R. G. Parr, Phys. Rev. B: Condens. Matter Mater. Phys., 1988, 37, 785-789.

53 P. J. Stephens, F. J. Devlin, C. F. Chablowski and M. J. Frisch, J. Phys. Chem., 1994, 98, 11623-11627.

54 T. W. Keal and D. J. Tozer, J. Chem. Phys., 2005, 123, 121103.

55 F. Weigend and R. Ahlrichs, Phys. Chem. Chem. Phys., 2005, 7, 3297-3305.

56 M. Dolf, U. Wedig, H. Stoll and H. Preuss, J. Chem. Phys., 1987, 86, 866-872.

57 P. Fuentealba, L. Vonszentpaly, H. Preuss and H. Stoll, J. Phys. B: At., Mol. Opt. Phys., 1985, 18, 1287-1296.

58 G. V. Lewis and C. R. A. Catlow, J. Phys. C: Solid State Phys., 1985, 18, 1149-1161.

59 W. Jost, J. Chem. Phys., 1933, 1, 466-475.

60 A. E. Hughes and B. Henderson, Color Centers in Simple Oxides, in Point Defects in Solids: General and Ionic Crystals, ed. J. H. Crawford and L. M. Slifkin, Springer US, Boston, MA, 1972, pp. 381-490.

61 F. Stavale, X. Shao, N. Nilius, H.-J. Freund, S. Prada, L. Giordano and G. Pacchioni, J. Am. Chem. Soc., 2012, 134, 11380-11383.

62 Y. Cui, X. Shao, S. Prada, L. Giordano, G. Pacchioni, H.-J. Freund and N. Nilius, Phys. Chem. Chem. Phys., 2014, 16, 12764-12772.

63 A. Walsh, J. Buckeridge, C. R. A. Catlow, A. J. Jackson, T. W. Keal, M. Miskufova, P. Sherwood, S. A. Shevlin, 
M. B. Watkins, S. M. Woodley and A. A. Sokol, Chem. Mater., 2013, 25, 2924-2926.

64 D. R. Lide, CRC Handbook of Chemistry and Physics, CRC Press, Boca Raton, Florida, 84th edn, 2003.

65 J. P. Perdew, K. Burke and M. Ernzerhof, Phys. Rev. Lett., 1996, 77, 3865-3868.

66 R. O. Jones and O. Gunnarsson, Rev. Mod. Phys., 1989, 61, 689-746.

67 T. Jaouen, G. Jézéquel, G. Delhaye, B. Lépine, P. Turban and P. Schieffer, Appl. Phys. Lett., 2010, 97, 232104.

68 R. Whited, C. J. Flaten and W. C. Walker, Solid State Commun., 1973, 13, 1903-1905.

69 R. D. Shannon, Acta Crystallogr., 1976, 32, 751-767.

70 L. N. Kantorovich, A. L. Shluger, P. V. Sushko, J. Gunster, P. Stracke, D. W. Goodman and V. Kempter, Faraday Discuss., 1999, 114, 173-194.

71 H. H. Kung, Transition metal oxides: surface chemistry and catalysis, Elsevier, 1989, vol. 45.
72 D. O. Scanlon, C. W. Dunnill, J. Buckeridge, S. A. Shevlin, A. J. Logsdail, S. M. Woodley, C. R. A. Catlow, M. J. Powell, R. G. Palgrave, I. P. Parkin, G. W. Watson, T. W. Keal, P. Sherwood, A. Walsh and A. A. Sokol, Nat. Mater., 2013, 12, 798-801.

73 S. A. French, A. A. Sokol, S. T. Bromley, C. R. A. Catlow, S. C. Rogers, F. King and P. Sherwood, Angew. Chem., Int. Ed., 2001, 40, 4437-4440.

74 A. Sokol, S. Bromley, S. French, C. Catlow and P. Sherwood, Int. J. Quantum Chem., 2004, 99, 695-712.

75 S. French, A. Sokol, S. Bromley, C. Catlow and P. Sherwood, Top. Catal., 2003, 24, 161-172.

76 S. Bromley, S. French, A. Sokol, C. Catlow and P. Sherwood, J. Phys. Chem. B, 2003, 107, 7045-7057.

77 C. Catlow, S. French, A. Sokol and J. Thomas, Philos. Trans. R. Soc., A, 2005, 363, 913-936.

78 Y. Cui, X. Shao, M. Baldofski, J. Sauer, N. Nilius and H.-J. Freund, Angew. Chem., Int. Ed., 2013, 52, 11385-11387. 